\title{
Astrocytes and disease: a neurodevelopmental perspective
}

\author{
Anna V. Molofsky, ${ }^{2,4}$ Robert Krenick, ${ }^{5}$ Erik Ullian, ${ }^{5}$ Hui-hsin Tsai, ${ }^{1,2,3}$ Benjamin Deneen, ${ }^{6}$ \\ William D. Richardson, ${ }^{7,8}$ Ben A. Barres, ${ }^{9}$ and David H. Rowitch ${ }^{1,2,3,10}$ \\ ${ }^{1}$ Department of Pediatrics, ${ }^{2}$ Department of Neurosurgery, Eli and Edythe Broad Center of Regeneration Medicine and Stem Cell \\ Research, ${ }^{3}$ Howard Hughes Medical Institute, University of California at San Francisco, San Francisco, California, 94143, USA; \\ ${ }^{4}$ Langley Porter Psychiatric Institute, San Francisco, California 94143, USA; ${ }^{5}$ Department of Ophthalmology, University of \\ California at San Francisco, San Francisco, California, 94143, USA; ${ }^{6}$ Department of Neuroscience, Baylor College of Medicine, \\ Houston, Texas 77030, USA; ${ }^{7}$ Wolfson Institute for Biomedical Research, ${ }^{8}$ Research Department of Cell and Developmental \\ Biology, University College London, London WC1E 6BT, United Kingdom; ${ }^{9}$ Department of Neurobiology, Stanford University, \\ Palo Alto, California 94305, USA
}

Astrocytes are no longer seen as a homogenous population of cells. In fact, recent studies indicate that astrocytes are morphologically and functionally diverse and play critical roles in neurodevelopmental diseases such as Rett syndrome and fragile $\mathrm{X}$ mental retardation. This review summarizes recent advances in astrocyte development, including the role of neural tube patterning in specification and developmental functions of astrocytes during synaptogenesis. We propose here that a precise understanding of astrocyte development is critical to defining heterogeneity and could lead advances in understanding and treating a variety of neuropsychiatric diseases.

Astrocytes are the most numerous cells in the mammalian brain, yet much remains to be learned about their molecular and functional characteristics. The dramatic increase in the number and complexity of glia during the course of evolution points to a role for astrocytes in the evolution of uniquely human traits such as cognition and further suggests that astrocytes likely play roles in neurological diseases. However, defining a role for astrocytes in developmental disorders has been hampered by a limited knowledge of how and when astrocytes develop, what they do, and the limited number of markers to identify and distinguish potentially heterogeneous astrocyte subtypes in animal models and in the human brain.

We propose here that a precise understanding of astrocyte development is critical to defining astrocyte heterogeneity. The functional complexity of the mammalian CNS is predicated on the ability to generate diverse cell types during development. This has been elegantly demonstrated for neurons, where cell-extrinsic developmen-

[Keywords: Rett syndrome; astrocyte; development; disease; heterogeneity; neurodevelopment; neuropsychiatric]

${ }^{10}$ Corresponding author.

E-mail rowitchd@peds.ucsf.edu.

Article is online at http://www.genesdev.org/cgi/doi/10.1101/gad.188326.112. tal signals and cell-intrinsic signaling cascades pattern neuronal progenitors to generate diverse types of neurons with unique morphological, electrophysiological, and molecular properties (for reviews, see Edlund and Jessell 1999; Miller and Gauthier 2007).

Similar principles might apply to glial biology. Although there are few studies focused specifically on the role of astrocytes, recent work provides important examples of how a better understanding of astrocyte developmental biology can inform our knowledge of human neurological disease. As we discuss below ("Astrocyte Development and Function in Neurodevelopmental Diseases"), in at least two diseases of neurodevelopment (Rett syndrome and fragile $\mathrm{X}$ syndrome), a compelling case can be made for pathological dysfunction of astrocytes. Although the dysfunctional proteins in both cases were thought to be expressed solely in neurons, they were later shown to have specific roles in astrocytes. Such vignettes serve to suggest the potential for glial developmental biology to inform our understanding of neurodevelopmental and psychiatric disease.

However, determining roles for astrocytes during development and disease will require new experimental approaches that can further resolve the intimate relationship between neurons and glia in the maturing brain. It is fascinating to consider how much more might be discovered from an astrocyte perspective for diseases such as autism, schizophrenia, and epilepsy, in which underlying mechanisms and genetic lesions are poorly understood. As we discuss below, the potential for advances is vast if new astrocyte markers, genetic tools, and insights into astrocyte development help to guide future research.

The purpose of this review is to summarize current concepts of astrocyte development in vivo, astrocyte function during development, and astrocytic contributions in several neurodevelopmental diseases. Roles for mature astrocytes (e.g., in synapse function and neurovascular modulation) (Stahl and Yancopoulos 1994; Bonni et al. 1997; Wang and Bordey 2008; Pfrieger 2009), re- 
active astrocytes (e.g., after inflammation and injury) (Murphy et al. 1997; Sofroniew 2009), and astrocytes in adult-onset neurological disease (Barnabé-Heider et al. 2005; Allaman et al. 2011) are the topics of several excellent recent reviews and are not covered in detail here. In each of the following sections, we conclude with a list of outstanding questions and future directions for research that include recommendations from the $\mathrm{Na}$ tional Institutes for Neurological Diseases and Stroke Workshop on Astrocyte Function in Health and Disease and National Institute for Mental Health (http://grants. nih.gov/grants/guide/rfa-files/RFA-MH-13-010.html).

\section{Practical considerations in astrocyte biology, astrocyte diversity, and model systems}

\section{Astrocyte heterogeneity: morphologic diversity and beyond}

Virchow first described glia as "nervenkitt" or nerve glue, implying a homogenous population of support cells with a mostly passive role (Somjen 1988). Detailed morphological studies over the subsequent years revealed the first broad category of astrocyte heterogeneity based on location in the white versus gray matter. Fibrous astrocytes populate the white matter: They typically have regular contours and cylindrical processes, yielding the more classic "starlike" appearance, and have dense glial filaments that stain with the intermediate filament marker GFAP (glial fibrillary acidic protein). Protoplasmic astrocytes populate the gray matter and have more irregular processes and few glial filaments (Vaughn and Pease 1967; Vaughn and Peters 1967; Bignami et al. 1972; Freeman 2010). Protoplasmic astrocytes contact and sheathe synapses by extending thousands of thin processes, with typically only one or two in contact with blood vessels or CNS boundaries (Bushong et al. 2002, 2003; Reichenbach et al. 2010) Some have suggested that fibrous and protoplasmic astrocytes may be developmentally distinct (Fig. 1; Miller and Raff 1984; Nishiyama et al. 2009).
In addition, there are two types of specialized "radial" astroglia recognized in the CNS. Bergmann glia are found in the cerebellum, with cell bodies in the Purkinje cell layer and processes that extend into the granule cell layer and terminate at the pial surface. Muller cells are the primary glial cell in the retina and are oriented radially, spanning the photoreceptor layer to the inner retinal surface (Metea and Newman 2006; Parpura and Haydon 2009). Both of these cell types are morphologically reminiscent of the radial glia cells present during CNS development. In fact, Bergmann glia serve an analogous function in helping to guide migrating granule cell precursors. However, in the adult CNS, the Bergmann and Muller glia are thought to functionally resemble protoplasmic astrocytes in that they associate with and enwrap synapses and may act to modulate synaptic function (Saijo et al. 2009; Reichenbach et al. 2010).

Evidence for developmental patterning of astrocytes and diversified astrocyte functions ("Emerging Concepts in Astrocyte Development: Specification and the Generation of Astrocyte Diversity" and "Astrocyte Function During Normal Development") suggest more than just morphological differences. Indeed, regional astrocyte heterogeneity has long been postulated based on coculture experiments showing differential neurite outgrowth and other characteristics from neurons grown on astrocytes from different brain regions (Prochiantz et al. 1987; Barbin et al. 1988; Vangeison and Rempe 2009). However, markers that can reliably identify subsets of astrocytes are only beginning to be described.

\section{Limitations and caveats of currently available astrocyte markers}

Developmental studies of neurons and oligodendrocytes in the past decade have relied on subtype and developmental stage-specific markers. In contrast, almost all studies of astrocyte development depend on GFAP expression, a marker of terminally differentiated astrocytes (Bignami et al. 1972; Allaman et al. 2011). GFAP poorly
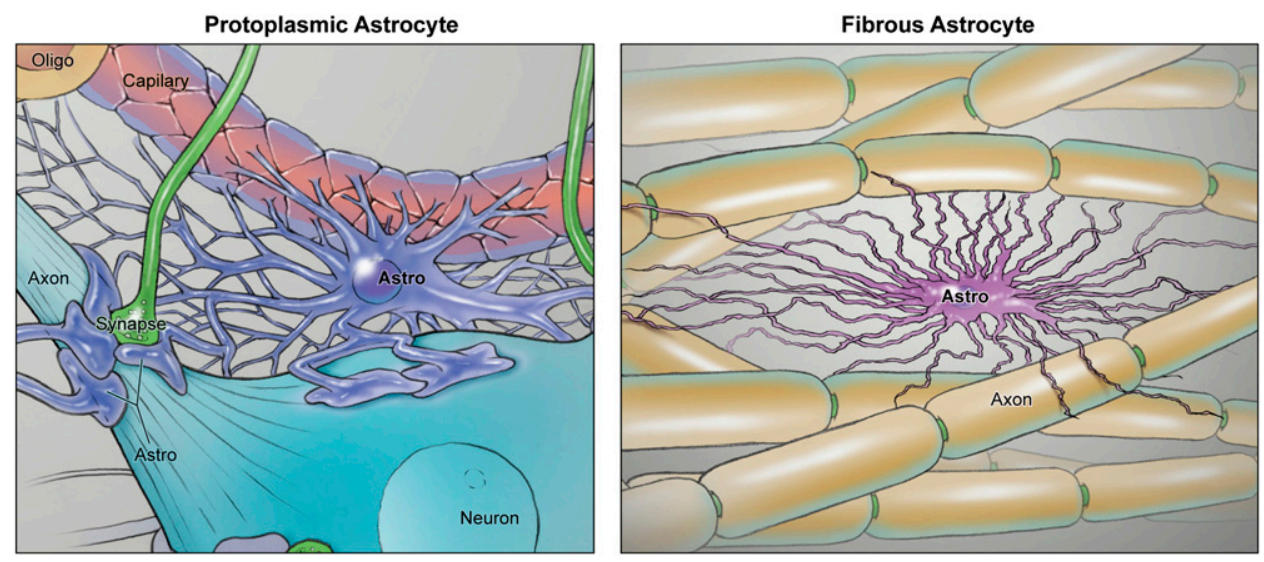

Figure 1. Astrocytes are morphologically heterogeneous. A protoplasmic astrocyte is shown in close connection with a neuron and a capillary, constituting the so-called "neurovascular unit" and highlighting the roles of astrocytes in developmental synaptogenesis and in modulating the BBB. (Right) A fibrous astrocyte is shown in a white matter tract, where it may interact with oligodendrocytes to promote myelination. 
labels protoplasmic astrocytes and is expressed late in development of fibrous astrocytes (Table 1). It is also expressed in adult type B multipotent cells of the rodent subventricular zone (SVZ), obviating its use as a stagespecific marker, and is up-regulated in reactive astrocytes and cultured astrocytes, reflecting a state quite different from that of normal resting astrocytes.

A developmental approach to astrocytogenesis has identified new potential markers of astrocyte precursors, with some limitations. For example, the first indication of glial specification is marked by the induction of nuclear factor I A/B (NFIA/B) (Deneen et al. 2006; Agulhon et al. 2010; Hamilton and Attwell 2010) and GLAST (Shibata et al. 1997; Araque and Navarrete 2010) at embryonic day 11.5 (E11.5). These markers continue to be expressed in astrocytes during precursor migration and are down-regulated in oligodendrocyte precursor populations (E13.5E16.5); thus, they do not become truly astrocyte-specific until several days post-specification in the VZ. Other reported markers of astrocytes and/or their precursors include S100- $\beta$ FGFR3 (Pringle et al. 2003; Ihrie and AlvarezBuylla 2008), FABP7 (Owada et al. 1996; Wolburg et al. 2009), BLBP (Anthony et al. 2004; Reichenbach et al. 2010), and Sox9 (Stolt et al. 2003; Rakic 2007). However, many of these markers are also expressed during neurogenic stages and thus do not exclusively mark astrocyte-committed VZ cells.
Expanding our knowledge of astrocyte markers, astrocyte heterogeneity, and how these may change during development will be critical to further advances. Recently, the application of gene expression profiling to purified astrocyte populations (Cahoy et al. 2008; Doyle et al. 2008; Fu et al. 2009; Rowitch and Kriegstein 2010) has revealed several potential new markers, such as the gene encoding the folate metabolic enzyme Aldh1L1 (Anthony and Heintz 2007; Cahoy et al. 2008; Ballas et al. 2009; Jacobs and Doering 2010). Iterative use of such approaches may yield better methods for isolating and analyzing developing and mature astrocytes.

\section{Model systems for studying astrocytes}

Much of our understanding of astroglial biology derives from investigation of mammalian systems, yet there is a striking conservation of the neuron-glial interaction throughout the invertebrate and vertebrate species, suggesting that some features of this interaction can be modeled in invertebrate systems such as Drosophila (Arber and Caroni 1995; Freeman 2010). Four morphologically distinct types of Drosophila glia have been described, some of which (cortex and neuropil glia) bear some superficial similarity to astrocytes (Freeman and Doherty 2006; Liauw et al. 2008; Edwards and Meinertzhagen 2010), while others seem more analogous to microglia (a mesodermal derivative in vertebrates).

Table 1. Markers of astrocytes and their progenitors

\begin{tabular}{|c|c|c|c|}
\hline Marker & $\begin{array}{l}\text { Expression } \\
\text { onset }\end{array}$ & Advantages & Caveats \\
\hline Glast & $\mathrm{mE} 11.5, \mathrm{cE} 5$ & Early expression & $\begin{array}{l}\text { Also expressed in some oligodendrocyte } \\
\text { precursors }\end{array}$ \\
\hline NFI A/B & $\mathrm{mE} 11.5, \mathrm{cE} 5-\mathrm{cE} 6$ & Early expression & $\begin{array}{l}\text { Also expressed in oligodendrocyte precursors } \\
\text { and mature motor neurons }\end{array}$ \\
\hline FABP7/BLBP & $\mathrm{mE} 8-\mathrm{mE} 9, \mathrm{cE} 2$ & Early expression & $\begin{array}{l}\text { Also expressed during neurogenic stages } \\
\text { in radial glia }\end{array}$ \\
\hline FGFR3 & $\mathrm{mE} 9.5, \mathrm{cE} 3$ & Early expression & $\begin{array}{l}\text { Also expressed during neurogenic stages in } \\
\text { radial glia and oligodendrocyte precursors }\end{array}$ \\
\hline Sox 9 & mE9.5-E10, cE3-cE4 & Early expression & As above \\
\hline Reelin/slit & $\mathrm{cE} 4$ & Early expression; subtype specificity & $\begin{array}{l}\text { Also expressed by neurons; uncharacterized } \\
\text { outside spinal cord }\end{array}$ \\
\hline AldhlL1 & mE9.5 & $\begin{array}{l}\text { Early expression that persists in mature } \\
\text { astrocytes; labels both fibrous and } \\
\text { protoplasmic astrocytes }\end{array}$ & $\begin{array}{l}\text { Incompletely characterized; expressed early in } \\
\text { radial glia, (unclear whether these are fated to } \\
\text { become astrocytes only) }\end{array}$ \\
\hline Id3 & $\mathrm{mE} 14.5$ & Early expression & $\begin{array}{l}\text { Also expressed in some } \\
\text { oligodendrocyte precursors }\end{array}$ \\
\hline Aldolase C & $\mathrm{mE} 15$ & $\begin{array}{l}\text { Antibody detects fibrous and protoplasmic } \\
\text { astrocytes }\end{array}$ & Also expressed in pial and purkinje cells \\
\hline GFAP & $\mathrm{mE} 17.5-\mathrm{mE} 18.5$ & $\begin{array}{l}\text { Robust, well-characterized marker of } \\
\text { mature fibrous astrocytes and } \\
\text { reactive astrocytes }\end{array}$ & $\begin{array}{l}\text { Poorly labels protoplasmic astrocytes; turned } \\
\text { on relatively late in development }\end{array}$ \\
\hline S100 $\beta$ & $\mathrm{mE} 15.5-\mathrm{mE} 16.5$ & Robust, good antibodies available & Also labels oligodendrocytes; turned on late \\
\hline Aquaporin-4 & $\mathrm{mE} 18$ & $\begin{array}{l}\text { Subtype specific? (preferentially labels } \\
\text { endfeet near blood vessels and pia) }\end{array}$ & Also in ependymal cells; white matter-restricted \\
\hline CD44 & E18.5-P0, cE10 & $\begin{array}{l}\text { Cell surface marker potentially } \\
\text { useful for flow cytometry }\end{array}$ & Incompletely characterized \\
\hline $\begin{array}{l}\text { Glutamine } \\
\text { synthetase }\end{array}$ & $\begin{array}{l}\text { Embryonic to } \\
\text { early postnatal }\end{array}$ & $\begin{array}{l}\text { Expressed in fibrous and } \\
\text { protoplasmic subtypes }\end{array}$ & Incompletely characterized \\
\hline
\end{tabular}

Note that onset of expression varies in different regions of the CNS, with marker detection generally sooner in spinal cord versus forebrain. See the text for details. (mE) Mouse embryonic day; (cE) chick embryonic day; (P) postnatal day. 
Important advances in our general understanding of glial function have been elucidated in Drosophila. This includes the role of glia in the phagocytosis of neurons during development, including the discovery of genes like draper (Awasaki et al. 2006; MacDonald et al. 2006). In other cases, conceptual paradigms of gliogenesis have been elucidated in invertebrate systems, such as the discovery in Drosophila of glial cells missing $(\mathrm{gcm})$ a single gene that regulates the neuron-glia switch. Notably, the function of this gene is not conserved in vertebrate gliogenesis (in fact, its homolog is not expressed in the nervous system at all) (Kim et al. 1998). Other model systems that could be used in the future to model aspects of vertebrate gliogenesis include Caenorhabditis elegans (Shaham 2006) and zebrafish (Grupp et al. 2010), which have already been exploited for new insights into oligodendrocyte biology.

However, the marked increase in the size and complexity of the nervous system has placed unique evolutionary pressures on glia as supporting players, perhaps accounting for the lack of conservation in glial specification genes such as $\mathrm{gcm}$. Known astrocyte functions such as interstitial buffering become orders of magnitude more complex when systems of neurons fire in synchrony. As such, it is not surprising to find a marked increase in the ratio of glia to neurons in higher mammals (Pfrieger 2009) as well as the complexity of the glia themselves. In fact, morphological analyses suggest that human protoplasmic astrocytes are larger and extend 10-fold more processes than their rodent counterparts (Oberheim et al. 2009). Thus, some roles of glia studied mainly in mouse models could be nonconserved or even more critical in primates and humans.

\section{Outstanding questions and future approaches}

Future advances in understanding how astrocytes contribute to diseases of neurodevelopment will rely heavily on the generation of new tools to study their development. As discussed above, a major limitation in the field is the lack of reliable markers. Once identified, relevant gene loci can be used to drive transgenes for fate mapping and functional analysis. Integration of recombinases (cre, FLP, or $\Psi$ X174) would allow fate mapping to confirm specificity to the astrocyte lineage. Because many genes show dynamic expression during development, further refinement could involve adding inducibility (mutant estrogen receptor or TET on/off systems.) Such regulatory elements could be used to drive conditionally inducible genes affecting astrocyte function, as has been done with oligodendrocyte precursors (Kessaris et al. 2006). The recent adaptation of optogenetic technologies to modulate astrocyte calcium signaling in vivo can be harnessed to achieve regional astrocyte dysfunction on a rapid and reversible scale (Gourine et al. 2010). Conserved activity of astrocyte regulatory elements defined in model systems could be assessed in human-derived astrocytes in order to model human disease. Finally, new markers of astrocytes should be developed into reagents that can be robustly applied in human neuropathological tissue.

\section{Emerging concepts in astrocyte development: specification and the generation of astrocyte diversity}

The differentiation of neural stem cells (NSCs) is a stepwise process that involves patterning, specification, migration, and terminal differentiation, often as part of a neural circuit. The concept of gliogenesis as homogenous throughout the CNS has undergone considerable evolution in recent years (Zhang and Barres 2010). An alternate view is that patterning influences at play in early CNS development strongly influence later gliogenic phases. Local cell-cell interactions influencing astrocytogenesis could also help to generate astrocyte diversity. However, as reviewed below, much remains to be learned about the ways in which astrocytes might be molecularly diverse and the functional implications of such diversity.

\section{Regulation of astrocytogenesis by transcription factors}

Vertebrate oligodendrogenesis is regulated by the distinct developmental processes of (1) pattern formation, (2) inhibition of neurogenesis and maintenance of a stem cell pool, (3) proglial transcriptional programs that specify committed precursors and their self-renewal, and (4) other programs to regulate migration and terminal differentiation. How this might apply to astrocyte specification is discussed below.

Neural tube pattern formation: Are astrocytes patterned? Neural tube patterning is the process by which cell-extrinsic patterning signals (Shh, BMP, and Wnts) are converted to cell-intrinsic differences in transcription factor expression. Patterning domains in the spinal cord (Jessell 2000) and forebrain (Sur and Rubenstein 2005) give rise to multiple classes of projection neurons and interneurons and thus have profound implications for the generation of neuronal diversity. The concept of patterning as a mechanism for generating astrocyte diversity has been recently reviewed (Rowitch 2004; Rowitch and Kriegstein 2010) and is briefly summarized below. See Figure 2 for more details.

Emerging data clearly support an instructive role for patterning in the generation of astrocytes. For example, our laboratory reported that a basic helix-loop-helix (bHLH) code is required for the development of V2b interneurons and astrocyte specification within the p2 progenitor domain (Muroyama et al. 2005). Further studies demonstrated a homeodomain code operating in ventral spinal cord white matter astrocytes whereby combinatorial expression of Pax6 and Nkx6.1 specifies three subtypes of ventral white matter astrocytes /termed VA1, VA2, and VA3), which can be identified in spinal cord white matter by graded expression of Reelin and Slit (Hochstim et al. 2008). These astrocyte subtypes are organized into domains of the ventral white matter along the dorsal-ventral axis, which mirror the arrangement of their progenitors in the $\mathrm{p} 1, \mathrm{p} 2$, and $\mathrm{p} 3 \mathrm{VZ}$ domains.

It remains to be determined whether such astrocytic patterning is a generalized principle throughout the CNS and whether it holds true for protoplasmic astrocytes. Furthermore, the implications of such patterning leave 


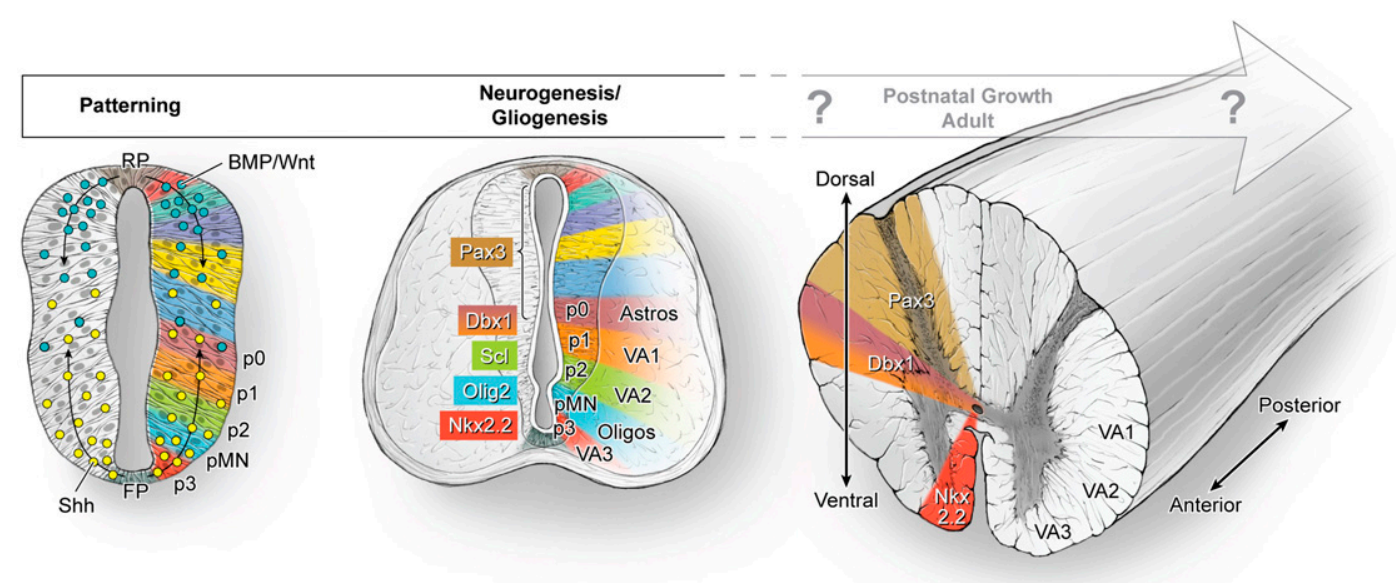

Figure 2. Neural tube patterning determines astrocyte identity in the developing spinal cord and influences astrocyte regional investment in adulthood. The neural tube is patterned via secretion of morphogens, including sonic hedgehog (SHH) from the floor plate and BMP/Wnts from the roof plate. This sets up domains of transcription factor expression, at least some of which have been shown to relate to specific white matter astrocyte subtypes in the ventral neural tube (VA1, VA2, and VA3). Whether this regional investment of astrocytes applies throughout the dorsal-ventral axis and whether it persists into adulthood is unknown. The right panel shows a hypothetical outcome, assuming strictly radial astrocyte migration.

many questions to be addressed. For example, neurons and oligodendrocytes are known to migrate widely from their sites of origin in the neural tube. Does the same apply to astrocytes, or do they remain positionally related to their site of origin? What aspects of astrocyte diversity are determined by their site of origin versus their eventual location? Finally, what are the functional implications of such developmental diversity?

The switch from neuron to glial production Differences in proliferation, differentiation, and/or migration could profoundly affect the local investment of astrocytes in the developing CNS. Multiple pathways that have been shown to play a role in gliogenesis may act by passively affecting the number of astrocytes by changing either the size of the progenitor pool or the timing of the neuronglia switch. A classic example is the notch pathway (Louvi and Artavanis-Tsakonas 2006; Pierfelice et al. 2011), which affects progenitor number but, on balance, has never been definitively shown to promote astrocytogenesis in an instructive manner (Ross et al. 2003).

In addition to delta-notch, a variety of transcription factors have been described that might directly or indirectly regulate precursor pool size and thereby gliogenesis. One example of this is N-CoR, a nuclear receptor corepressor for multiple transcription factors, including the notch effector RBP-J (CBF-1) (Gaiano and Fishell 2002). It is highly expressed in NSC populations and is also associated with the repression of astrocytogenesis. NSC populations from $\mathrm{N}$-CoR-deficient mice failed to proliferate in the presence of FGF2 and rapidly formed astrocytic colonies that expressed GFAP (Hermanson et al. 2002). This finding, together with precocious induction of GFAP, suggests that $\mathrm{N}-\mathrm{CoR}$ represses astrogenesis in vivo. Part of the mechanism may involve forming a complex with the neuregulin receptor Erb4, which can then bind astrocytic genes and repress their expression (Sardi et al. 2006). This is an example of how processes that maintain NSC self-renewal inhibit the generation of astrocytes.

Conversely, the neurogenin (ngn1-3) family of bHLH transcription factors is an example of how proneurogenic factors may impede astrocytogenesis. Individual overexpression of either ngn 1 (Sun et al. 2001) or ngn2 (Roybon et al. 2008) blocks astrocytogenesis in vitro. Deletion of ngn2 alone leads to an accumulation of radial glial-like progenitors in the VZ but no obvious increase in astrocytogenesis (Andersson et al. 2006; Kele et al. 2006; Galichet et al. 2008), perhaps due to compensatory up-regulation of the proneural gene Mash1 (Fode et al. 1998). However, progenitors from Ngn2/Mash1 double-knockout embryos have an increased probability of astrocyte formation in culture (Nieto et al. 2001). Thus, the data would seem to favor a role for proneural factors like neurogenins in inhibiting gliogenesis, in the case of $\mathrm{Ngn1}$, by sequestering the CBP/p300/Smad1 complex away from glial-specific promoters (Sun et al. 2001).

Proglial programs: Sox 9 and NIFA/B promote astrocytogenesis One of the main driving forces in the identification of new astrocyte markers during development has been the discovery of transcription factors that promote astrocytogenesis. The elucidation of other such factors will help to expand our understanding of astrocyte specification and generation and provide tools for manipulating astrocytes at different stages of development.

NFIA: NFI genes are a family of transcription factors that bind CAATT boxes and control the initiation of gliogenesis in the embryonic spinal cord and the differentiation of astrocytes later in gliogenesis. NFIA is induced at E11.5 in the VZ (Deneen et al. 2006). Gain-of- 
function and loss-of-function manipulations in the embryonic chick spinal cord indicate that NFIA expression is necessary and sufficient for gliogenesis (Deneen et al. 2006). Furthermore, misexpression studies yielded precocious induction of astrocyte precursor markers, indicating that it functions to instruct the astrocyte fate. An additional role of NFIA is to passively suppress neurogenesis via maintenance of Notch signaling via Hes genes (Kang et al. 2012). Thus, Notch signaling coordinates the inhibition of neurogenesis and maintenance of the progenitor pool with processes that initiate gliogenesis.

Individual knockout of NFIA or NFIB in mice results in relatively mild defects in the expression of astrocyte precursor markers (das Neves et al. 1999; Shu et al. 2003; Steele-Perkins et al. 2005), likely due to compensation by the remaining NFI family members. However, analysis at later embryonic stages revealed a drastic decrease in the expression of GFAP in the embryonic brain and spinal cord, indicating that both these genes are necessary for astrocyte differentiation in vivo (das Neves et al. 1999; Steele-Perkins et al. 2005). These findings are supported by several in vitro studies indicating that NFI genes directly regulate the expression of GFAP during astrocyte differentiation in various cell systems, including human and mouse neural progenitors (Cebolla and Vallejo 2006; Wilczynska et al. 2009). In addition to direct regulation of GFAP, NFIA may potentiate STAT3 activation of GFAP in vitro by epigenetic mechanisms (Namihira et al. 2009). This seems to occur in a Notch-dependent manner, thus providing a biochemical link between STAT3, NFIA, and Notch signaling and suggesting an active role for Notch during astrocytogenesis, at least in some cortical progenitor cultures.

Sox9: Sox9 is an HMG box transcription factor that is expressed in NSC populations in the embryonic spinal cord and developing retina. It is first detected in VZ precursors at E10.5, $1 \mathrm{~d}$ prior to induction of NFIA. Conditional knockout of Sox 9 in the developing mouse spinal cord via nestin-cre (Stolt et al. 2003) led to an extended period of neurogenesis coupled with a significant delay in the onset of gliogenesis. There was eventual recovery of the oligodendrocyte pool but a reduction in the generation of astrocytes. Close inspection of the knockout mice indicates that Sox 9 may be particularly important for gray matter (protoplasmic) astrocytes (identified by staining with GLAST and glutamine synthetase), suggesting a possible role in astrocyte diversification.

The timing of Sox9 induction in the embryonic spinal cord suggests a possible regulatory role in gliogenesis but does not clarify whether such a role would be instructive or permissive. However, recent data demonstrate that Sox9 is required for the induction of NFIA and subsequent gliogenesis (Kang et al. 2012). Using a combination of in vivo enhancer screening and gene manipulation in chicks and mice, Kang et al. (2012) showed that Sox9 directly regulates the induction of NFIA during the initiation of gliogenesis. Tests of epistasis in chicks revealed that Sox 9 induction of NFIA is necessary for gliogenesis, and biochemical studies revealed that they physically associate and collaborate to regulate a set of genes that are specifically expressed in VZ populations after E11.5. A subset of these genes, Apcdd1 and Mmd2, perform key migratory and metabolic roles, respectively, during subsequent stages of astrogliogenesis. Thus, Sox9 and NFIA comprise a transcriptional cascade that controls the initiation of gliogenesis and later collaborate to execute multiple genetic programs that regulate the physiology of astroglial precursors.

Local environmental signals in astrocyte generation and diversification The Il-6 family of regulatory cytokines is a family of morphogens (Miller and Gauthier 2007) whose receptors bind to gp130, thereby activating the Jak/Stat pathway (Stahl and Yancopoulos 1994; Bonni et al. 1997). Many early findings in cell culture are consistent with a model in which activation of CNTF/LIF receptors promote glial maturation (as assessed by GFAP expression) coincident with other signaling pathways that determine gliogenesis versus neurogenesis (Murphy et al. 1997).

A recent study implicates the cytokine cardiotrophin-1 (ct-1) as the in vivo ligand for the CNTF/LIF receptor. CT1 -deficient mice had $50 \%-80 \%$ decreases in GFAP expression in certain cortical regions perinatally (BarnabéHeider et al. 2005). In the forebrain, ct-1 is expressed in newborn neurons, and ablation of this neuron-derived CT-1 inhibited expression of GFAP in cultured cortical precursors. This suggests that CT-1 may be secreted from newborn neurons to promote subsequent astrogenesis, implicating cell-cell interactions in astrocytogenesis, although whether they direct specification or maturation cannot be determined, as these studies relied solely on expression of the late stage marker GFAP. It is unknown whether further signals in the astrocyte target environment could affect astrocyte maturation; for example, by directing final maturation into fibrous or protoplasmic astrocytes.

\section{Postnatal astrocyte maturation}

Although astrocyte proliferation and diversification are largely complete by early postnatal stages, the process of elaborating and refining astrocytic processes continues well into postnatal development and coincides with a period of active synaptogenesis in which astrocytes play a crucial part (Freeman 2010). Data from dye-filling experiments suggest that protoplasmic astrocytic processes are initially fillopodial and later develop spatially segregated nonoverlapping domains (Bushong et al. 2002, 2003). Developmental changes in fibrous astrocytes are less well understood, but could, in principle, be studied using similar mechanisms. Mature astrocyte markers such as GFAP, Aquaporin-4, and S-100 $\beta$ are increasingly up-regulated during postnatal maturation. A better understanding of this stage of astrocyte development will be important for clarifying the role of astrocytes in postnatal synaptogenesis and understanding how defects in synaptogenesis underlie certain neurodevelopmental diseases (see below.) 


\section{Outstanding questions and future approaches}

This section highlighted evidence for proastrocytic programs and a segmental template for astrocyte development, implying that heterogeneity is built into the system at an early stage and raising many further questions. For example, what are the combinatorial codes of transcription factors that determine astrocyte subtype identity? This problem is complex in execution, since, in contrast to neurons, which develop during an early embryonic first wave, astrocytes might derive additional signals from their neighboring neurons. Simple misspecification of pattern domains by gain-of-function or loss-of-function approaches, as has been widely applied for the analysis of neuron subtype specification, is therefore complicated with respect to gliogenesis. To circumvent this, new tools would be required to alter the transcriptional code specifically during the gliogenic phase while leaving first-wave neurogenesis intact.

What is the nature of astrocyte precursors? Do all astrocytes derive directly from radial glial progenitors in the VZ, or is there an additional stage of expansion that occurs through an "intermediate astrocyte precursor"? Another cell type that has been proposed for several decades is the putative glial-restricted precursor cell that gives rise to both astrocytes and oligodendrocytes (Raff et al. 1983; for review, see Rowitch and Kriegstein 2010). Defining markers for astrocytes at early stages of development should yield a more definitive understanding of the nature and potential of astrocyte precursors.

It is also important to understand the signaling pathways that regulate the expansion and migration of astrocyte precursor populations. The density of astrocytes differs widely between different regions of the CNS. This may reflect the region-restricted expression of mitogenic cues or the cellular competence of certain populations of astrocytes to respond to such cues. For example, RAS signaling has been shown to regulate the proliferation of astrocyte precursor cells in region-specific ways /Yeh et al. 2009). Such information is relevant to both astrocyte development and how dysregulation in these pathways could lead to glial neoplasms. In addition, how do astrocytes migrate during normal development? Do they travel along restricted radial trajectories, as indicated in some studies (Gray and Sanes 1991), or might they employ multimodal migration to invest various regions of the CNS, as suggested by numerous transplant experiments (Zhou et al. 1990; Jacobsen and Miller 2003)?

Finally, there is the question of how developmental heterogeneity relates to astrocyte functional heterogeneity. As detailed in the section below, astrocytes have diverse functions, many of which are brain region-specific. Ablating astrocytes from specific brain regions or identifying and deleting functional astrocyte genes that are expressed in a region-specific manner (such as extracellular matrix molecules, secreted signaling molecules, and so forth) would be important next steps. Ultimately, clarifying whether developmental astrocyte heterogeneity leads to diverse astrocyte functions will be critical to understanding how abnormalities in astrocyte development could lead to disease.

\section{Astrocyte function during normal development}

The notion that astrocytes are important for brain function is certainly no longer novel. In the adult brain, it is well accepted that astrocytes influence multiple aspects of synaptic transmission by maintaining extracellular homeostasis (Parpura and Haydon 2009). As a result, astrocytes are critical to promoting neuronal survival in the context of neuroinflammation (Saijo et al. 2009) and hypoxia (Vangeison and Rempe 2009), among others (Allaman et al. 2011). Although controversial, many groups have also argued that astrocytes, like neurons, actively engage in information processing (Agulhon et al. 2010; Hamilton and Attwell 2010). A corollary to this is the idea that astrocytes may participate in synaptic plasticity in regions such as the hypothalamus and the hippocampus (Araque and Navarrete 2010).

In the adult CNS, astrocytes are also known to serve a number of regional functions. For example, in the SVZ, a germinal region of the adult brain, astrocyte-like cells that express GFAP serve as stem/progenitor cells that give rise to adult-born neurons in the olfactory bulb of rodents (Ihrie and Alvarez-Buylla 2008). As part of the glia limitans, the region of the brain that separates cerebrospinal fluid from the extravascular space, astrocytes are crucial components of the blood-brain barrier (BBB) (Wolburg et al. 2009). Bergmann glia of the cerebellum and Muller glia in the retina may also serve region-specific functions in guiding cell migration during development (Reichenbach et al. 2010).

\section{The function of radial glia and astrocyte precursors during embryonic development}

What would a developmental perspective on astrocyte function look like? First, it is important to clarify that astrocytes at different stages of embryonic and postnatal development are morphologically, and probably functionally, different. Although specific markers for the different stages of astrocytogenesis are not available, we can speculate that astrogenesis progresses through at least four stages: a radial glial progenitor, a proliferating intermediate progenitor, a maturing postnatal astrocyte, and an adult astrocyte. The first glial cells—radial glia-serve crucial roles in brain development from the earliest stages of development by both serving as neural progenitors and providing the scaffolds along which newborn neurons migrate tangentially (Rakic 2007; Rowitch and Kriegstein 2010). Following the cessation of neurogenesis during mid-gestation, radial glia become gliogenic and give rise to proliferating astrocyte and oligodendrocyte precursors.

Due to the relatively recent identification of early stage markers such as Aldh1L1, the function of immature astrocytes during late embryogenesis has not been studied. Some possible functions include guiding ongoing neuronal migrations via the secretion of extracellular matrix proteins or signaling molecules and regulating dendritic and axonal growth. Multiples studies have found that mutant astrocytes variably modify dendritic outgrowth of hippocampal neurons in culture (Ballas 
et al. 2009; Jacobs and Doering 2010). In addition, thrombospondins (TSPs), best known for their roles in promoting synaptogenesis, also promote neurite outgrowth in some developmental contexts (Arber and Caroni 1995) and axonal sprouting after injury (Liauw et al. 2008). A more detailed exploration of how immature astrocytes affect the early stages of dendritic growth in vivo would require a better understanding of genes that affect astrocyte function without affecting total astrocyte number and the ability to delete those genes in astrocytes (Fig. 3).

\section{Maturing astrocytes promote synaptogenesis in developing postnatal brains}

As discussed above, early postnatal astrocytes are actively extending processes and refining functional territories. Additionally, as recent research has demonstrated, they are also actively promoting synapse formation. The protracted postnatal maturation of the mammalian nervous system is a balance between synaptogenesis and synapse stabilization/elimination (Pfrieger 2009). In a series of studies from the Barres laboratory (Pfrieger and Barres 1997; Ullian et al. 2001), it was first demonstrated that purified retinal ganglion cells make many more synapses when cocultured with astrocytes, even in the absence of direct contact, which suggested the presence of a secreted molecule from astrocytes that promotes neuronal synapse formation. Similar effects were found in cultured spinal motor neurons (Ullian et al. 2004).

The Barres laboratory (Christopherson et al. 2005; Eroglu et al. 2009) identified the proteins involved as TSPs, a group of matricellular proteins that are expressed in astrocytes of the developing but not mature brain, and TSP1/2deficient mice were shown to have reduced numbers of synapses in vivo. Further work identified the neuronal TSP receptor involved, which is also a receptor for the anti-epileptic and analgesic gabapentin (Eroglu et al. 2009). Other molecules that may also be involved in astrocyte-induced synaptogenesis include cholesterol, integrins, ephrins, and others (for review, see Pfrieger 2009). Most recently, astrocyte-secreted proteins Hevin and Sparc were shown to influence excitatory CNS synaptogenesis both in vitro and in the superior colliculus in vivo-Hevin by promoting synaptogenesis, and sparc by specifically inhibiting hevin function (Kucukdereli et al. 2011). Despite the critical role of TSPs in promoting synaptogenesis, additional signals are likely required for synapse maturation, as TSP-induced synapses are

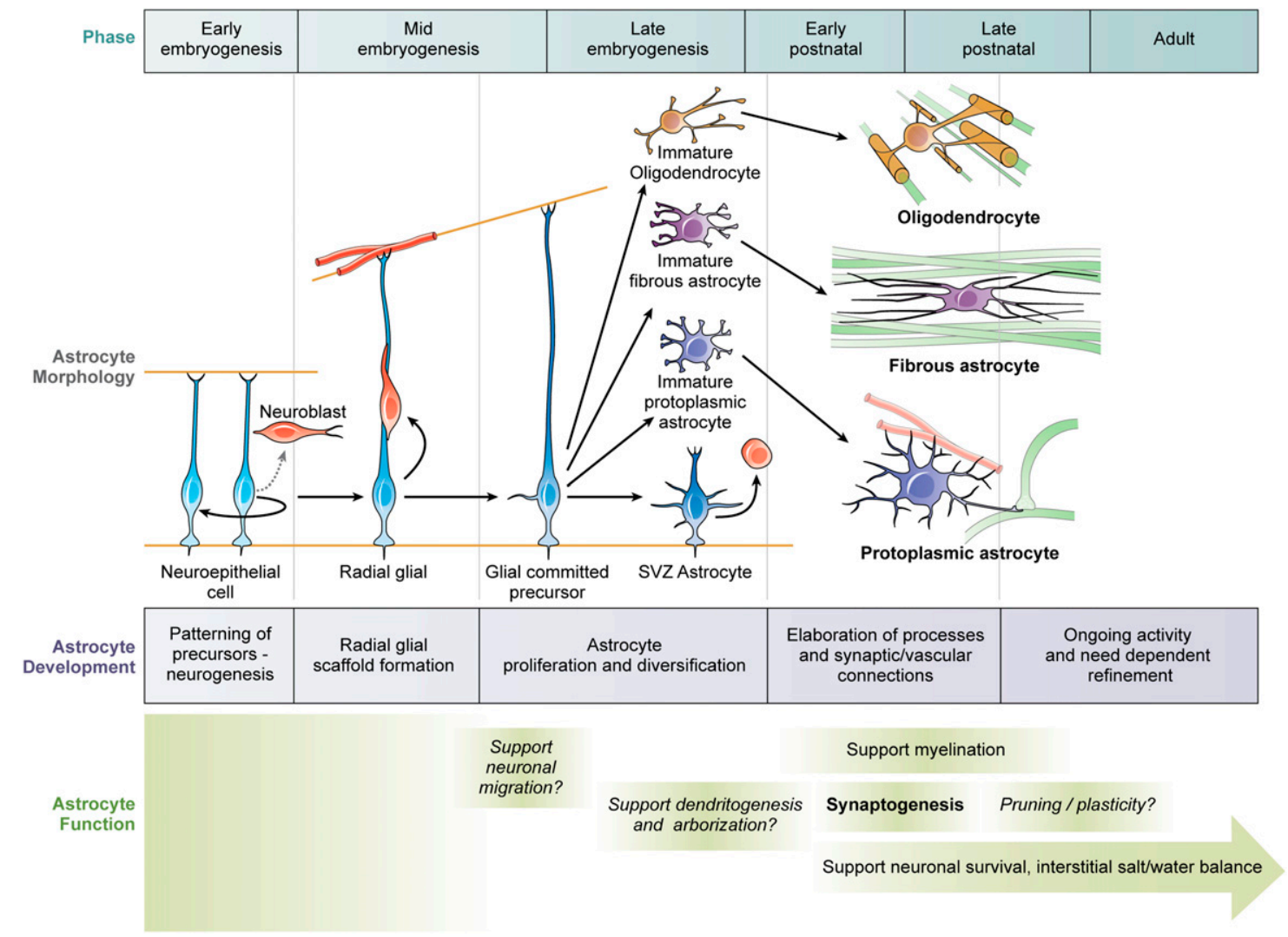

Figure 3. Astrocyte morphology and function changes across developmental time. Neuroepithelial cells give rise to radial glia, which generate first neurons, and then become glial-committed, giving rise to precursors that proliferate and diversify into fibrous and protoplasmic astrocytes, which then go through a protracted stage of postnatal maturation. Astrocyte precursors at these different stages of maturation serve well-established stage-specific roles in assisting myelination and synaptogenesis and may also influence other functions, such as neuronal migration, pruning, and so forth. Well-established adult roles for astrocytes, including supporting neuronal survival and homeostasis, likely develop in parallel. 
ultrastructurally normal but postsynaptically silent. Allen et al. (2011) have taken a biochemical approach to identify two closely homologous glypicans-glypican-4 and glypican-6-as astrocyte-secreted proteins that are sufficient to increase AMPA glutamate receptor levels on synapses, thus inducing postsynaptic function.

\section{Other possible developmental functions of astrocytes}

Synapse stabilization and elimination The formation of stable synapses is a dynamic process in which synaptic connections are made and eliminated in an activitydependent manner (Luo and O'Leary 2005). Notably, excessive synapse elimination in the prefrontal cortex has been proposed as a possible pathophysiological mechanism in schizophrenia (Keshavan et al. 1994; Insel 2010). Studies in Drosophila have clearly demonstrated a role for glia in neuronal engulfment during the pruning of Drosophila mushroom body neurons during metamorphosis (Awasaki et al. 2006, 2011) and in the Drosophila neuromuscular junction (Fuentes-Medel et al. 2009). Homologous proteins expressed by glia mediate a similar process in mouse embryonic dorsal root ganglia (Wu et al. 2009). In the mammalian reticulogeniculate system, it has been demonstrated that the classical complement cascade mediates synapse elimination. Purified retinal ganglion cells in contact with astrocytes greatly increase secretion of $\mathrm{Clq}$, the initiating protein in the complement cascade, suggesting that astrocytes may be involved in this process (Stevens et al. 2007), although other glial cells, particularly microglia, which also highly express $\mathrm{Clq}$, are likely to play a significant role.

Myelination Myelination is a critical feature of postnatal brain development and maturation. The close temporal relationship between the development of astrocytes and oligodendrocytes raises the question of whether astrocytes may play a role in assisting myelination. Furthermore, a leukodystrophy clearly caused by astrocyte dysfunction-Alexander's disease-emphasizes the idea that astrocyte development and normal white matter function are likely closely correlated (see below). In fact, studies of myelination in culture suggest that astrocytes may play a role by helping to align oligodendrocyte processes with axons (Meyer-Franke 1999) and that they promote myelination in response to electrical impulses by an ATP- and LIF-dependent mechanism (Ishibashi et al. 2006). Although they are not directly involved in myelination, they may increase the rate of myelin wrapping, as demonstrated in an in vitro coculture system (Watkins et al. 2008).

Maintenance of the $B B B$ In the adult brain, astrocytic endfeet form a sheathing network around the brain vasculature known as the glia limitans, which, together with pericytes and endothelial cells, form a barrier to the passage of molecules, ions, and cells from the bloodstream into the brain parenchyma: the BBB. It is known that in this context, astrocytes play an important role in the regulation of cerebral blood flow (Takano et al. 2006; Attwell et al.
2010) as well as in regulating BBB permeability from the bloodstream into the brain parenchyma. Defects in the BBB are involved in many adult disease states, including neurodegenerative and neuroinflammatory diseases (Zlokovic 2008).

In culture, astrocytes induce formation of the BBB (Janzer and Raff 1987). However, in vivo, a relatively functional $\mathrm{BBB}$ is present by E15, before large numbers of astrocytes have been generated (Daneman et al. 2010). In addition, BBB formation is compromised in pericyte-deficient mouse models (Armulik et al. 2010; Daneman et al. 2010). Thus, while at least two groups have demonstrated a requirement for pericytes in BBB formation, the role of astrocytes in this process is still unclear. In addition, much remains to be learned about how astrocytes might modulate BBB development during late embryogenesis and after birth (Quaegebeur et al. 2011). Given the close coupling between astrocytes and neurons that forms the neurovascular unit in adulthood (Allaman et al. 2011), it is likely that its development must also be tightly regulated in order to coordinate developing cerebral vascular supply to neuronal demand.

\section{Outstanding questions and future approaches}

The sections above highlighted the role of maturing astrocytes in myelination and neural circuit formation. It is increasingly clear that developing astrocytes serve unique roles and are molecularly distinct from their adult counterparts. For example, TSPs are expressed only in early postnatal astrocytes and become down-regulated by adulthood (Christopherson et al. 2005). The various roles proposed for astrocytes also suggest that there may be regional functional heterogeneity between brain regions based on local requirements for synaptogenesis, myelination, and other support functions. As discussed in "Emerging Concepts in Astrocyte Development: Specification and the Generation of Astrocyte Diversity," the degree to which regional functional heterogeneity may be related to astrocyte developmental patterning is unknown.

How can this functional heterogeneity be further defined at the molecular level?

First, it involves prospective identification of astrocytespecific yet regionally heterogeneous expression. This could be identified through interrogation of existing databases (e.g., the Allen Brain Atlas), enhancer trap studies (e.g., GENSAT), or discovery of developmental gene regulatory pathways specific for subsets of astrocytes. Second, whole-genome, proteome, and metabolomic approaches might distinguish functional subsets of astrocytes. Third, prospective isolation of region-specific astrocytes followed by coculture with neurons might suggest functionally diverse properties of astrocytes, including synaptogenesis, electrophysiological properties, myelination, and axon guidance.

A final question is whether region-specific roles for astrocytes can be applied to better understand the nature of human neurological and neurodegenerative diseases. For example, given the evidence for an astroglial role in amyotrophic lateral sclerosis (ALS), which affects ventral 
horn motor neurons, it would be interesting to determine whether astrocytes in the region of motor neurons might be specifically affected by disease-causing mutations. A more detailed discussion of emerging roles for astrocytes in neurodevelopmental diseases follows below.

\section{Astrocyte development and function in neurodevelopmental diseases}

A gliocentric approach to neuropsychiatric disease has the potential to revolutionize our understanding of disease pathogenesis and treatment. Indeed, detailed analyses of neurodevelopmental diseases with known genetic lesions (and their corresponding mouse models) are beginning to reveal that astrocyte dysfunction during development results in disease pathology. These include Rett syndrome, fragile X mental retardation, Alexander's disease, and others. A common finding of many of these studies is that astrocyte dysfunction has profound noncell-autonomous effects on surrounding neurons; thus, understanding the mechanisms of astrocyte dysfunction will be critical to future therapeutic strategies.

\section{Rett syndrome}

Rett syndrome, an X-linked neurodevelopmental disorder, is caused by the loss of the transcriptional repressor methyl-CpG-binding protein 2 (MeCP2.) Clinical features of the disease include autism, respiratory abnormalities, cognitive impairment, loss and regression of early developmental milestones, and a decrease in brain weight and volume (Chahrour and Zoghbi 2007). Mice lacking the MeCP2 gene recapitulate many features of the human disease and suggest a critical window for MeCP2 function during postnatal development (Giacometti et al. 2007; Guy et al. 2007).

Early studies showed that expression of Mecp2 in postmitotic neurons led to variable recovery from the cellular and behavioral phenotypes of Mecp2 deficiency; these groups also failed to detect MeCP2 in glia (Chen et al. 2001; Luikenhuis et al. 2004). More recently, improved antibodies have detected its expression in multiple types of cultured glia, including GFAP-positive astrocytes, NG2positive oligodendrocyte progenitor cells, and MBP-positive mature oligodendrocytes (Ballas et al. 2009; Zoghbi 2009). Furthermore, Ballas et al. (2009) found that wildtype hippocampal neurons cocultured with cortical astrocytes or conditioned medium from Mecp2-deficient mice had abnormally stunted dendrites, suggesting that Mecp2deficient astrocytes may dominantly affect normal neuronal development. This is particularly relevant in the case of human Rett syndrome, where mosaic expression of the Mecp2 gene means that $50 \%$ of neurons are initially healthy and may be damaged by secreted factors from mutant astrocytes.

A follow-up study found that conditional reactivation of MeCP2 only in GFAP-positive cells partially rescued defects in Mecp2-deficient mice, including behavioral measures (locomotor activity and respiratory patterns) and neuroanatomical parameters (neuronal soma diame- ter, hippocampal dendritic branching, and expression of the synaptic vesicle protein vGlut1) (Lioy et al. 2011). Taken together, the evidence suggests that loss of MeCP2 function in astrocytes contributes to the developmental defects in neurons of Mecp2-deficient mice, with the caveat that the hGFAP promoter can affect some neurons $(<5 \%$ in this study). Thus, it is difficult to entirely rule out a neuronal contribution to the rescue. This raises the important question of how astrocytic dysfunction may be involved in human Rett syndrome, with the potential for an even greater role given the increasing complexity of astrocytes from mice to humans (Oberheim et al. 2009).

\section{Fragile $X$ mental retardation}

Fragile $\mathrm{X}$ syndrome, the most common cause of inherited mental retardation, is caused by mutation of FMR1. Patients show cognitive impairment, autistic features, attention deficits, increased rates of epilepsy, and motor abnormalities (Beckel-Mitchener and Greenough 2004). In humans, polyglutamine repeats in the FMR1 gene lead to loss of FMRP protein expression. In mice, knocking out FMR1 leads to a phenotype that recapitulates many of the clinical and cell-biological features of the disease, including abnormal dendritic spine development.

While many studies had detected expression of FMRP in neurons, more recent immunohistochemical studies demonstrate FMRP expression in developing astrocytes in vitro and possibly in vivo as well, although markers other than GFAP will be necessary to confirm such expression in vivo (Pacey and Doering 2007). Hippocampal neurons grown on FMR1-deficient astrocytes show abnormal dendritic morphology relative to those grown on wild-type astrocytes (Jacobs and Doering 2010), and the intrinsic dendritic defects of FMR1-deficient neurons are significantly rescued when these cells are grown on a monolayer of wild-type rather than FMR1-deficient astrocytes. FMR1-deficient astrocytes may also have some effect on synapse formation, at least in culture, although culture conditions also play a significant role in this system (Jacobs et al. 2010). Thus, both neuronal and astrocytic compartments may contribute to the measurable phenotypes in the FMR1 mutants. This raises the possibility that the in vivo defects in dendritic spine development are at least partly related to neuron-glia interactions during development.

\section{Alexander's disease}

Alexander's disease is currently the only known disease due to a mutation in an astrocyte-specific protein-GFAP. Clinically, it is characterized by macrocephaly, abnormal white matter, and developmental delay and is most commonly diagnosed in its infantile form, with onset before 2 yr of age (Quinlan et al. 2007). The cardinal pathologic finding of cytoplasmic GFAP aggregates in astrocytes led to the discovery that gain-of-function point mutations in GFAP are responsible for the disease (Quinlan et al. 2007). Understanding of the genetic basis of Alex- 
ander's disease has helped explain clinical heterogeneity of the disorder, as some individuals with GFAP point mutations have later onset or less severe symptoms than others. The exact mechanism of astrocyte dysfunction is unclear, but the presence of white matter injury indicates effects on oligodendrocytes and myelination. Another inherited leukodystrophy that may involve astrocyte dysfunction is the lysosomal storage disorder Niemann-Pick type $\mathrm{C}$ disease, as the recently identified causative protein NPC1 was found localized primarily in astrocytic processes (Patel et al. 1999), and NP-C-deficient astrocytes showed some defects in cholesterol metabolism in culture (Patel et al. 1994).

A possible role for astrocytes in other genetic diseases with neurocognitive delay

Another broad category of human neurological disorders that may involve astrocytes are the "RASopathies." These affect components of the Ras/MapK signaling pathway and include neurofibromatosis type-1 and Noonan, Leopard, CFC, and Costello syndromes. Clinical features across these disorders are variable, but frequently include varying degrees of neurocognitive delay (for review, see Tidyman and Rauen 2009). Studies in animal models suggest that signal dysregulation in these genetic diseases alters the timing of astrogliogenesis (Gauthier et al. 2007), raising the possibility that altered astrocyte development contributes to the underlying mental impairments. Another neurocognitive disorder that may also involve timing of astrocyte development is Down syndrome (Trisomy 21). Recent work has shown that human neural progenitors from Down syndrome patients show a gliogenic shift and corresponding decrease in neurogenesis (Lu et al. 2011). Although the data for astrocyte dysfunction in the aforementioned disorders are still preliminary, these studies raise the important possibility that defects affecting the earliest stages of astrocytogenesis could have profound impacts on the developing brain.

\section{Epilepsy}

Much is known about the role of mature and reactive astrocytes in epileptogenesis via their effects on glutamate transport and release and their roles in buffering potassium and interstitial volume control (Wetherington et al. 2008; Benarroch 2009).

While astrocytic inclusions have been observed in some cases of pediatric epilepsy (Hazrati et al. 2008; Visanji et al. 2012), the possible developmental role of astrocytes in shaping a predisposition to epileptogenesis is unclear. However, not all genetic causes of developmental delay and decreased cognitive function predispose to epilepsy. It is notable that of those that do, including Rett syndrome, fragile X mental retardation, and tuberous sclerosis, two have been recently shown to have developmental defects in postnatal astrocyte function (Prince and Ring 2011). For example, 10\%-20\% of children with fragile $\mathrm{X}$ syndrome also have epilepsy (Hagerman and Stafstrom 2009), and up to $80 \%$ of cases of Rett syndrome have seizures (Jian et al. 2006).

It has been shown that astrocyte dysfunction in adult model systems is involved in abnormal neuronal excitability (Gómez-Gonzalo et al. 2010) and that inducing reactive astrocytosis leads to the formation of epileptic foci in the hippocampus (Ortinski et al. 2010). These findings, along with the recent discovery that astrocytes modulate postnatal synaptogenesis ("Astrocyte Function During Normal Development," above), beg the question of whether abnormal astrocyte development could also alter the excitatory-inhibitory balance of the developing brain and predispose to epileptogenesis. Similar arguments apply to the study of autism, as described below.

\section{Autism}

Autism spectrum disorders (ASDs) are neurodevelopmental disorders characterized by varying degrees of impaired social interaction and communication, with boys being affected four times more commonly than girls. Although the molecular mechanisms of ASDs are poorly understood, models of autism pathology emphasize the idea that abnormal synapse development underlies many features of the disease and postulate abnormalities in excitatory-inhibitory balance (Rubenstein 2010). This conclusion is based in part on the finding that many of the genes associated with autism are involved in postnatal synaptogenesis (Walsh et al. 2008). In fact, it is notable that the same neurodevelopmental diseases that present with epilepsy are also commonly associated with ASDs, such that the strongest genetic association to autism yet known is mutations in FMR1 (Beckel-Mitchener and Greenough 2004). Taken together, the known roles for astrocytes in modulating normal synapse development postnatally and in vitro evidence of their role in fragile $\mathrm{X}$ pathogenesis suggest that a better understanding of astrocyte function or dysfunction in ASDs will shed light on pathogenesis and the development of new treatment strategies.

\section{'Adult-onset' psychiatric diseases}

Multiple studies have demonstrated changes in glial cell number or characteristics in the adult brains of patients with psychiatric disorders or in mouse models, including reductions in GFAP levels in prefrontal cortical and corticolimbic areas in a rat model of depression (Gosselin et al. 2009) and decreases in glial density in the amygdala in post-mortem samples of patients with depression (Altshuler et al. 2010). Consistent with these findings, loss of GFAP-positive cells in the adult rat prefrontal cortex by injection of a gliotoxin led to increased depressive-like behaviors (Banasr and Duman 2008). In schizophrenia, although changes in the expression level of GFAP are not consistently observed, one study found massive up-regulation of extracellular matrix proteins in the entorhinal cortex astrocytes of schizophrenic patients (Pantazopoulos et al. 2010), suggesting a disruption in astrocyte function. 
While many of these disorders present in early adulthood and thus were not traditionally seen as diseases of neurodevelopment, recent evidence favors a developmental model of these diseases, particularly schizophrenia (Insel 2010). Schizophrenia is predominantly defined by the presence of psychosis (hallucinations and delusions), and multiple lines of evidence support the idea that cortical "dysconnectivity," as a result of aberrant postnatal development, may be responsible for psychotic symptoms (Weinberger and Lipska 1995; Raedler et al. 1998). Further attention to the roles of astrocytes is warranted, given their roles in postnatal synaptogenesis and myelination.

Although the literature on a neurodevelopmental hypothesis of depression is more recent, a leading model for how neurodevelopmental defects may lead to depressive phenotypes later in life involves the increased risk for depression following prenatal or early life stress. Given that gliogenesis is a major feature during this stage of brain development, it is not surprising that several mouse models of early stress find later defects in glial cell density. For example, maternal restraint during the gliogenic period of pregnancy (E13-E17) led to a reduction in postnatal glial cell density in the hippocampus of female mice and correlated with increased measures of anhedonia and cognitive performance (Behan et al. 2011). Similarly, early life stress in the form of early postnatal deprivation led to reduced GFAP-positive astrocytes in regions of the brain associated with stress-related behavior, including the prefrontal cortex, cingulate cortex, amygdala, and certain hippocampal regions (Leventopoulos et al. 2007).

Finally, a recurrent theme in psychiatric diseases is the preferential dysfunction in specific brain regions, such as the prefrontal cortex, limbic system, and hippocampus. Many imaging studies have demonstrated volumetric changes in specific brain regions that could be related to glial cell loss or hypertrophy. Even more notable, noninvasive functional brain imaging techniques such as fMRI rely on measurements of neurovascular coupling (changes in blood flow to neurons), which occurs through astrocyte intermediates (Schummers et al. 2008; Petzold and Murthy 2011; Quaegebeur et al. 2011). Thus, understanding the molecular and developmental basis for astrocyte regional heterogeneity could help elucidate why and how specific brain regions or circuits are affected in different psychiatric diseases.

\section{Outstanding questions and future approaches}

Understanding the role of astrocytes in human neurological and psychiatric diseases requires a comprehensive picture of how astrocytes develop and what roles they play in development. Conversely, human diseases could provide clues to subtle astrocyte functions during development that may take years to manifest clinically. One example is Huntington's disease (HD), which may involve astrocyte dysfunction (Bradford et al. 2009) and is increasingly thought to have a neurodevelopmental component that precedes the onset of clinical symptoms
(Mehler and Gokhan 2000). HD and other astrocyterelated neurodegenerative diseases, including ALS, demonstrate that astrocyte dysfunction can have non-cellautonomous effects on surrounding tissues (Lobsiger and Cleveland 2007).

With regards to psychiatric diseases, it will be important to understand how astrocytes modulate synaptic development and function in the circuits that mediate cognition, affect, and social function. An equally challenging question is whether gene-environment developmental interactions might be regulated at the level of astrocyte function. Progress on these questions will require advances in our understanding of the genetic underpinnings of psychiatric and neurological disease and will call for new animal disease models that reflect gene-environment interactions and developmental processes.

Recent work has shown the feasibility of deriving functional astrocytes from embryonic stem cells and from reprogrammed induced pluripotent stem cells (Gupta et al. 2011; Krencik et al. 2011). Importantly, the in vitro differentiation process follows in vivo developmental stages in which stem cell-derived neuroepithelial cells transition from a multipotent neural progenitor into a more restricted astroglial progenitor over time. This technology allows for an accessible human cellular system for studies of neurodevelopment. Use of patient-derived astrocytes will be important to the study of many neurological and psychiatric disorders that involve astrocyte function, both those for which the genetic lesions are well understood (Rett, fragile $\mathrm{X}$, and the "RASopathies") and those that are less well defined (schizophrenia and autism.) Another advantage of stem cell culture is that patterning molecules can be added during the neuroepithelial stage to specify progenitors to regionally distinct pools (Fig. 4), mimicking the in vivo patterning described above in a controlled environment. This allows for the generation of various astrocyte subtypes to study intrinsic markers of human astrocyte diversity and may provide functionally specific astrocytes for studying regionspecific diseases; e.g., midbrain astrocytes in the case of Parkinson's disease or ventral-spinal astrocytes in ALS.

Ultimately, new developments in understanding glialbased diseases must incorporate a more sophisticated understanding of glial development and incorporate new tools to study astrocyte function. Future astrocyte-based therapies will require understanding the mechanisms of astrocyte dysfunction in disease. These tools will emerge from a better understanding of astrocyte specification, patterning, regional and temporal heterogeneity, and function. Understanding not only where and why but also when things go wrong will be critical to future glial-based therapeutics. Furthermore, the concepts discussed in this review, as applied to neurodevelopmental disorders, will provide a wealth of new tools for the investigation of neurodegenerative disorders of adults. It is increasingly clear that a comprehensive understanding of diseases of neurodevelopment as well as those of the mature brain will require a sophisticated knowledge of the ubiquitous astrocyte. 


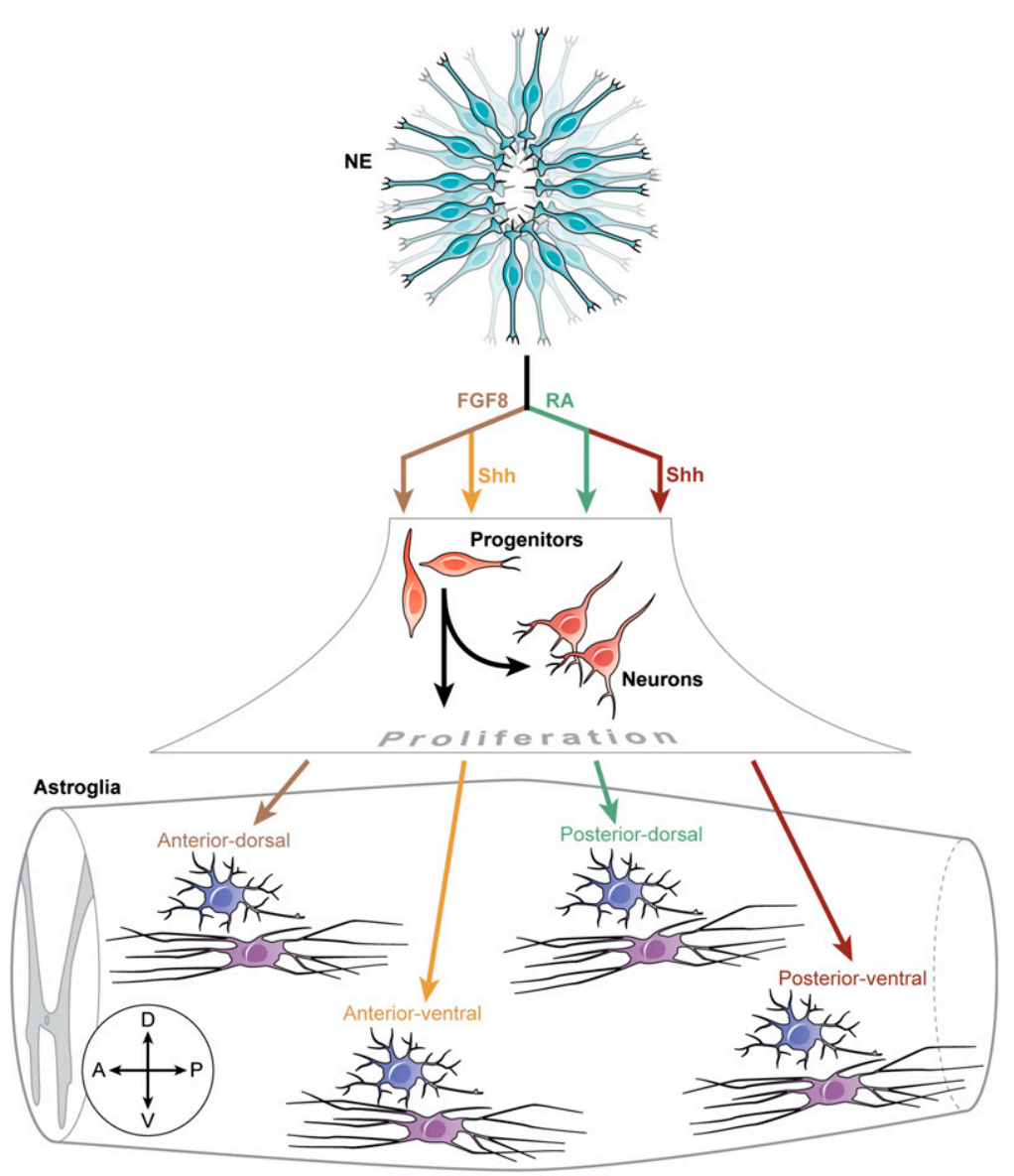

Figure 4. Recapitulation of human astrocyte diversity in vitro. Human stem cell-derived neuroepithelial cells (NE) can be patterned into regionspecific neural progenitor subtypes by the addition of morphogens. After an extended differentiation into a gliogenic-restricted stage, the resultant astroglial cells retain the positional code, similar to cells generated throughout the entire axis of the neural tube. This culture system allows for studies of the functional consequences of astrocyte diversity in the absence of unknown environmental variables that are present in vivo and provides a human disease model by using astrocytes generated from patientspecific induced pluripotent stem cells.

\section{Acknowledgments}

We apologize to those whose work we could not cite owing to space limitations. We thank Dr. Devanand Manoli for helpful comments on the manuscript, and Kenneth Probst for assistance with figures. D.H.R., B.A.B., and W.D.R. acknowledge support from a grant from the NINDS (NS059893). D.H.R is a Howard Hughes Medical Institute Investigator.

\section{Note added in proof}

Since this manuscript was submitted, two new studies have been published further elucidating the cellular and molecular mechanisms controlling astrocyte population expansion (Ge et al. 2012; Tien et al. 2012).

\section{References}

Agulhon C, Fiacco TA, McCarthy KD. 2010. Hippocampal short- and long-term plasticity are not modulated by astrocyte $\mathrm{Ca}^{2+}$ signaling. Science 327: 1250-1254.

Allaman I, Bélanger M, Magistretti PJ. 2011. Astrocyte-neuron metabolic relationships: For better and for worse. Trends Neurosci 34: 76-87.

Allen NJ, Chakraborty C, Howe ML, Barres BA. 2011. Identification of an astrocyte-derived factor that promotes the formation of excitatory synapses containing GluA1 AMPA glutamate receptors. Program no. 436.10/A61. Neuroscience Meeting Planner. Society for Neuroscience, Washington, DC. Online.

Altshuler LL, Abulseoud OA, Foland-Ross L, Bartzokis G, Chang S, Mintz J, Hellemann G, Vinters HV. 2010.
Amygdala astrocyte reduction in subjects with major depressive disorder but not bipolar disorder. Bipolar Disord 12: 541-549.

Andersson E, Jensen JB, Parmar M, Guillemot F, Björklund A. 2006. Development of the mesencephalic dopaminergic neuron system is compromised in the absence of neurogenin 2. Development 133: 507-516.

Anthony TE, Heintz N. 2007. The folate metabolic enzyme ALDH1L1 is restricted to the midline of the early CNS, suggesting a role in human neural tube defects. I Comp Neurol 500: 368-383.

Anthony TE, Klein C, Fishell G, Heintz N. 2004. Radial glia serve as neuronal progenitors in all regions of the central nervous system. Neuron 41: 881-890.

Araque A, Navarrete M. 2010. Glial cells in neuronal network function. Philos Trans $R$ Soc Lond B Biol Sci 365: 23752381.

Arber S, Caroni P. 1995. Thrombospondin-4, an extracellular matrix protein expressed in the developing and adult nervous system promotes neurite outgrowth. J Cell Biol 131: 10831094.

Armulik A, Genové G, Mäe M, Nisancioglu MH, Wallgard E, Niaudet C, He L, Norlin J, Lindblom P, Strittmatter K, et al. 2010. Pericytes regulate the blood-brain barrier. Nature 468: 557-561.

Attwell D, Buchan AM, Charpak S, Lauritzen M, Macvicar BA, Newman EA. 2010. Glial and neuronal control of brain blood flow. Nature 468: 232-243.

Awasaki T, Tatsumi R, Takahashi K, Arai K, Nakanishi Y, Ueda R, Ito K. 2006. Essential role of the apoptotic cell engulfment 
genes draper and ced-6 in programmed axon pruning during Drosophila metamorphosis. Neuron 50: 855-867.

Awasaki T, Huang Y, O'Connor MB, Lee T. 2011. Glia instruct developmental neuronal remodeling through TGF- $\beta$ signaling. Nat Neurosci 14: 821-823.

Ballas N, Lioy DT, Grunseich C, Mandel G. 2009. Non-cell autonomous influence of MeCP2-deficient glia on neuronal dendritic morphology. Nat Neurosci 12: 311-317.

Banasr M, Duman RS. 2008. Glial loss in the prefrontal cortex is sufficient to induce depressive-like behaviors. Biol Psychiatry 64: 863-870.

Barbin G, Katz DM, Chamak B, Glowinski J, Prochiantz A. 1988. Brain astrocytes express region-specific surface glycoproteins in culture. Glia 1: 96-103.

Barnabé-Heider F, Wasylnka JA, Fernandes KJL, Porsche C, Sendtner M, Kaplan DR, Miller FD. 2005. Evidence that embryonic neurons regulate the onset of cortical gliogenesis via cardiotrophin-1. Neuron 48: 253-265.

Beckel-Mitchener A, Greenough WT. 2004. Correlates across the structural, functional, and molecular phenotypes of fragile X syndrome. Ment Retard Dev Disabil Res Rev 10: 53-59.

Behan AT, van den Hove DLA, Mueller L, Jetten MJA, Steinbusch HWM, Cotter DR, Prickaerts J. 2011. Evidence of femalespecific glial deficits in the hippocampus in a mouse model of prenatal stress. Eur Neuropsychopharmacol 21: 71-79.

Benarroch EE. 2009. Astrocyte-neuron interactions: Implications for epilepsy. Neurology 73: 1323-1327.

Bignami A, Eng LF, Dahl D, Uyeda CT. 1972. Localization of the glial fibrillary acidic protein in astrocytes by immunofluorescence. Brain Res 43: 429-435.

Bonni A, Sun Y, Nadal-Vicens M, Bhatt A, Frank DA, Rozovsky I, Stahl N, Yancopoulos GD, Greenberg ME. 1997. Regulation of gliogenesis in the central nervous system by the JAKSTAT signaling pathway. Science 278: 477-483.

Bradford J, Shin J-Y, Roberts M, Wang C-E, Li X-J, Li S. 2009. Expression of mutant huntingtin in mouse brain astrocytes causes age-dependent neurological symptoms. Proc Natl Acad Sci 106: 22480-22485.

Bushong EA, Martone ME, Jones YZ, Ellisman MH. 2002. Protoplasmic astrocytes in CAl stratum radiatum occupy separate anatomical domains. J Neurosci 22: 183-192.

Bushong EA, Martone ME, Ellisman MH. 2003. Examination of the relationship between astrocyte morphology and laminar boundaries in the molecular layer of adult dentate gyrus. I Comp Neurol 462: 241-251.

Cahoy JD, Emery B, Kaushal A, Foo LC, Zamanian JL, Christopherson KS, Xing Y, Lubischer JL, Krieg PA, Krupenko SA, et al. 2008. A transcriptome database for astrocytes, neurons, and oligodendrocytes: A new resource for understanding brain development and function. J Neurosci 28: 264-278.

Cebolla B, Vallejo M. 2006. Nuclear factor-I regulates glial fibrillary acidic protein gene expression in astrocytes differentiated from cortical precursor cells. J Neurochem 97: 1057-1070.

Chahrour M, Zoghbi HY. 2007. The story of Rett syndrome: From clinic to neurobiology. Neuron 56: 422-437.

Chen RZ, Akbarian S, Tudor M, Jaenisch R. 2001. Deficiency of methyl-CpG binding protein-2 in CNS neurons results in a Rett-like phenotype in mice. Nat Genet 27: 327-331.

Christopherson KS, Ullian EM, Stokes CCA, Mullowney CE, Hell JW, Agah A, Lawler J, Mosher DF, Bornstein P, Barres BA. 2005. Thrombospondins are astrocyte-secreted proteins that promote CNS synaptogenesis. Cell 120: 421-433.

Daneman R, Zhou L, Kebede AA, Barres BA. 2010. Pericytes are required for blood-brain barrier integrity during embryogenesis. Nature 468: 562-566. das Neves L, Duchala CS, Tolentino-Silva F, Haxhiu MA, Colmenares C, Macklin WB, Campbell CE, Butz KG, Gronostajski RM, Godinho F. 1999. Disruption of the murine nuclear factor I-A gene (Nfia) results in perinatal lethality, hydrocephalus, and agenesis of the corpus callosum. Proc Natl Acad Sci 96: 11946-11951.

Deneen B, Ho R, Lukaszewicz A, Hochstim CJ, Gronostajski RM, Anderson DJ. 2006. The transcription factor NFIA controls the onset of gliogenesis in the developing spinal cord. Neuron 52: 953-968.

Doyle JP, Dougherty JD, Heiman M, Schmidt EF, Stevens TR, Ma G, Bupp S, Shrestha P, Shah RD, Doughty ML, et al. 2008. Application of a translational profiling approach for the comparative analysis of CNS cell types. Cell 135: 749-762.

Edlund T, Jessell TM. 1999. Progression from extrinsic to intrinsic signaling in cell fate specification: A view from the nervous system. Cell 96: 211-224.

Edwards TN, Meinertzhagen IA. 2010. The functional organisation of glia in the adult brain of Drosophila and other insects. Prog Neurobiol 90: 471-497.

Eroglu C, Allen NI, Susman MW, O'Rourke NA, Park CY, Ozkan E, Chakraborty C, Mulinyawe SB, Annis DS, Huberman $\mathrm{AD}$, et al. 2009. Gabapentin receptor $\alpha 2 \delta-1$ is a neuronal thrombospondin receptor responsible for excitatory CNS synaptogenesis. Cell 139: 380-392.

Fode C, Gradwohl G, Morin X, Dierich A, LeMeur M, Goridis C, Guillemot F. 1998. The bHLH protein NEUROGENIN 2 is a determination factor for epibranchial placode-derived sensory neurons. Neuron 20: 483-494.

Freeman MR. 2010. Specification and morphogenesis of astrocytes. Science 330: 774-778.

Freeman MR, Doherty J. 2006. Glial cell biology in Drosophila and vertebrates. Trends Neurosci 29: 82-90.

Fu H, Cai J, Clevers H, Fast E, Gray S, Greenberg R, Jain MK, Ma Q, Qiu M, Rowitch DH, et al. 2009. A genome-wide screen for spatially restricted expression patterns identifies transcription factors that regulate glial development. J Neurosci 29: 11399-11408.

Fuentes-Medel Y, Logan MA, Ashley J, Ataman B, Budnik V, Freeman MR. 2009. Glia and muscle sculpt neuromuscular arbors by engulfing destabilized synaptic boutons and shed presynaptic debris. PLOS Biol 7: e1000184. doi: 10.1371/ journal.pbio.1000184.

Gaiano N, Fishell G. 2002. The role of notch in promoting glial and neural stem cell fates. Annu Rev Neurosci 25: 471-490.

Galichet C, Guillemot F, Parras CM. 2008. Neurogenin 2 has an essential role in development of the dentate gyrus. Development 135: 2031-2041.

Gauthier AS, Furstoss O, Araki T, Chan R, Neel BG, Kaplan DR, Miller FD. 2007. Control of CNS cell-fate decisions by SHP-2 and its dysregulation in Noonan syndrome. Neuron 54: 245262.

Ge WP, Miyawaki A, Gage FH, Jan YN, Jan LY. 2012. Local generation of glia is a major astrocyte source in postnatal cortex. Nature doi: 10.1038/nature10959.

Giacometti E, Luikenhuis S, Beard C, Jaenisch R. 2007. Partial rescue of MeCP2 deficiency by postnatal activation of MeCP2. Proc Natl Acad Sci 104: 1931-1936.

Gómez-Gonzalo M, Losi G, Chiavegato A, Zonta M, Cammarota M, Brondi M, Vetri F, Uva L, Pozzan T, de Curtis M, et al. 2010. An excitatory loop with astrocytes contributes to drive neurons to seizure threshold. PLOS Biol 8: e1000352. doi: 10.1371/journal.pbio.1000352.

Gosselin R-D, Gibney S, O'Malley D, Dinan TG, Cryan JF. 2009. Region specific decrease in glial fibrillary acidic protein 
immunoreactivity in the brain of a rat model of depression. Neuroscience 159: 915-925.

Gourine AV, Kasymov V, Marina N, Tang F, Figueiredo MF, Lane S, Teschemacher AG, Spyer KM, Deisseroth K, Kasparov S. 2010. Astrocytes control breathing through $\mathrm{pH}$-dependent release of ATP. Science 329: 571-575.

Gray GE, Sanes JR. 1991. Migratory paths and phenotypic choices of clonally related cells in the avian optic tectum. Neuron 6: 211-225.

Grupp L, Wolburg H, Mack AF. 2010. Astroglial structures in the zebrafish brain. J Comp Neurol 518: 4277-4287.

Gupta K, Patani R, Baxter P, Serio A, Story D, Tsujita T, Hayes JD, Pedersen RA, Hardingham GE, Chandran S. 2011. Human embryonic stem cell derived astrocytes mediate noncell-autonomous neuroprotection through endogenous and drug-induced mechanisms. Cell Death Differ doi: 10.1038/ cdd.2011.154.

Guy J, Gan J, Selfridge J, Cobb S, Bird A. 2007. Reversal of neurological defects in a mouse model of Rett syndrome. Science 315: 1143-1147.

Hagerman PJ, Stafstrom CE. 2009. Origins of epilepsy in fragile $\mathrm{X}$ syndrome. Epilepsy Curr 9: 108-112.

Hamilton NB, Attwell D. 2010. Do astrocytes really exocytose neurotransmitters? Nat Rev Neurosci 11: 227-238.

Hazrati L-N, Kleinschmidt-DeMasters BK, Handler MH, Smith ML, Ochi A, Otsubo H, Rutka JT, Go C, Weiss S, Hawkins CE. 2008. Astrocytic inclusions in epilepsy: Expanding the spectrum of filaminopathies. I Neuropathol Exp Neurol 67: 669-676.

Hermanson O, Jepsen K, Rosenfeld MG. 2002. N-CoR controls differentiation of neural stem cells into astrocytes. Nature 419: 934-939.

Hochstim C, Deneen B, Lukaszewicz A, Zhou Q, Anderson DJ. 2008. Identification of positionally distinct astrocyte subtypes whose identities are specified by a homeodomain code. Cell 133: 510-522.

Ihrie RA, Alvarez-Buylla A. 2008. Cells in the astroglial lineage are neural stem cells. Cell Tissue Res 331: 179-191.

Insel TR. 2010. Rethinking schizophrenia. Nature 468: 187-193.

Ishibashi T, Dakin KA, Stevens B, Lee PR, Kozlov SV, Stewart CL, Fields RD. 2006. Astrocytes promote myelination in response to electrical impulses. Neuron 49: 823-832.

Jacobs S, Doering LC. 2010. Astrocytes prevent abnormal neuronal development in the fragile $\mathrm{X}$ mouse. I Neurosci 30: $4508-4514$.

Jacobs S, Nathwani M, Doering LC. 2010. Fragile X astrocytes induce developmental delays in dendrite maturation and synaptic protein expression. BMC Neurosci 11: 132. doi: 10.1186/1471-2202-11-132.

Jacobsen CT, Miller RH. 2003. Control of astrocyte migration in the developing cerebral cortex. Dev Neurosci 25: 207-216.

Janzer RC, Raff MC. 1987. Astrocytes induce blood-brain barrier properties in endothelial cells. Nature 325: 253-257.

Jessell TM. 2000. Neuronal specification in the spinal cord: Inductive signals and transcriptional codes. Nat Rev Genet 1: 20-29.

Jian L, Nagarajan L, de Klerk N, Ravine D, Bower C, Anderson A, Williamson S, Christodoulou J, Leonard H. 2006. Predictors of seizure onset in Rett syndrome. J Pediatr 149: 542547.

Kang P, Lee HK, Glasgow SM, Finley M, Donti T, Gaber ZB, Graham BH, Foster AE, Novitch BG, Gronostajski RM, et al. 2012. Sox9 and NFIA coordinate a transcriptional regulatory cascade during the initiation of gliogenesis. Neuron (in press).

Kele J, Simplicio N, Ferri ALM, Mira H, Guillemot F, Arenas E, Ang S-L. 2006. Neurogenin 2 is required for the development of ventral midbrain dopaminergic neurons. Development 133: 495-505.

Keshavan MS, Anderson S, Pettegrew JW. 1994. Is schizophrenia due to excessive synaptic pruning in the prefrontal cortex? The Feinberg hypothesis revisited. I Psychiatr Res 28: 239265.

Kessaris N, Fogarty M, Iannarelli P, Grist M, Wegner M, Richardson WD. 2006. Competing waves of oligodendrocytes in the forebrain and postnatal elimination of an embryonic lineage. Nat Neurosci 9: 173-179.

Kim J, Jones BW, Zock C, Chen Z, Wang H, Goodman CS, Anderson DJ. 1998. Isolation and characterization of mammalian homologs of the Drosophila gene glial cells missing. Proc Natl Acad Sci 95: 12364-12369.

Krencik R, Weick JP, Liu Y, Zhang Z-J, Zhang S-C. 2011. Specification of transplantable astroglial subtypes from human pluripotent stem cells. Nat Biotechnol 29: 528-534.

Kucukdereli H, Allen NJ, Lee AT, Feng A, Ozlu MI, Conatser LM, Chakraborty C, Workman G, Weaver M, Sage EH, et al. 2011. Control of excitatory CNS synaptogenesis by astrocyte-secreted proteins Hevin and SPARC. Proc Natl Acad Sci 108: E440-E449. doi: 10.1073/pnas.1104977108.

Leventopoulos M, Rüedi-Bettschen D, Knuesel I, Feldon J, Pryce CR, Opacka-Juffry J. 2007. Long-term effects of early life deprivation on brain glia in Fischer rats. Brain Res 1142: 119-126.

Liauw J, Hoang S, Choi M, Eroglu C, Choi M, Sun G-H, Percy M, Wildman-Tobriner B, Bliss T, Guzman RG, et al. 2008. Thrombospondins 1 and 2 are necessary for synaptic plasticity and functional recovery after stroke. I Cereb Blood Flow Metab 28: 1722-1732.

Lioy DT, Garg SK, Monaghan CE, Raber J, Foust KD, Kaspar BK, Hirrlinger PG, Kirchhoff F, Bissonnette JM, Ballas N, et al. 2011. A role for glia in the progression of Rett's syndrome. Nature 475: 497-500.

Lobsiger CS, Cleveland DW. 2007. Glial cells as intrinsic components of non-cell-autonomous neurodegenerative disease. Nat Neurosci 10: 1355-1360.

Louvi A, Artavanis-Tsakonas S. 2006. Notch signalling in vertebrate neural development. Nat Rev Neurosci 7: 93-102.

Lu J, Esposito G, Scuderi C, Steardo L, Delli-Bovi LC, Hecht JL, Dickinson BC, Chang CJ, Mori T, Sheen V. 2011. S100B and APP promote a gliocentric shift and impaired neurogenesis in Down syndrome neural progenitors. PLOS ONE 6: e22126. doi: 10.1371/journal.pone.0022126.

Luikenhuis S, Giacometti E, Beard CF, Jaenisch R. 2004. Expression of MeCP2 in postmitotic neurons rescues Rett syndrome in mice. Proc Natl Acad Sci 101: 6033-6038.

Luo L, O'Leary DDM. 2005. Axon retraction and degeneration in development and disease. Annu Rev Neurosci 28: 127-156.

MacDonald JM, Beach MG, Porpiglia E, Sheehan AE, Watts RJ, Freeman MR. 2006. The Drosophila cell corpse engulfment receptor Draper mediates glial clearance of severed axons. Neuron 50: 869-881.

Mehler MF, Gokhan S. 2000. Mechanisms underlying neural cell death in neurodegenerative diseases: Alterations of a developmentally-mediated cellular rheostat. Trends Neurosci 23: 599-605.

Metea MR, Newman EA. 2006. Calcium signaling in specialized glial cells. Glia 54: 650-655.

Meyer-Franke A. 1999. Astrocytes induce oligodendrocyte processes to align with and adhere to axons. Mol Cell Neurosci 14: 385-397.

Miller FD, Gauthier AS. 2007. Timing is everything: Making neurons versus glia in the developing cortex. Neuron 54: 357-369. 
Miller RH, Raff MC. 1984. Fibrous and protoplasmic astrocytes are biochemically and developmentally distinct. I Neurosci 4: 585-592.

Muroyama Y, Fujiwara Y, Orkin SH, Rowitch DH. 2005. Specification of astrocytes by bHLH protein SCL in a restricted region of the neural tube. Nature 438: 360-363.

Murphy M, Dutton R, Koblar S, Cheema S, Bartlett P. 1997. Cytokines which signal through the LIF receptor and their actions in the nervous system. Prog Neurobiol 52: 355-378.

Namihira M, Kohyama J, Semi K, Sanosaka T, Deneen B, Taga T, Nakashima K. 2009. Committed neuronal precursors confer astrocytic potential on residual neural precursor cells. Dev Cell 16: 245-255.

Nieto M, Schuurmans C, Britz O, Guillemot F. 2001. Neural bHLH genes control the neuronal versus glial fate decision in cortical progenitors. Neuron 29: 401-413.

Nishiyama A, Komitova M, Suzuki R, Zhu X. 2009. Polydendrocytes (NG2 cells): Multifunctional cells with lineage plasticity. Nat Rev Neurosci 10: 9-22.

Oberheim NA, Takano T, Han X, He W, Lin JHC, Wang F, Xu Q, Wyatt JD, Pilcher W, Ojemann JG, et al. 2009. Uniquely hominid features of adult human astrocytes. J Neurosci 29: 3276-3287.

Ortinski PI, Dong J, Mungenast A, Yue C, Takano H, Watson DJ, Haydon PG, Coulter DA. 2010. Selective induction of astrocytic gliosis generates deficits in neuronal inhibition. Nat Neurosci 13: 584-591.

Owada Y, Yoshimoto T, Kondo H. 1996. Spatio-temporally differential expression of genes for three members of fatty acid binding proteins in developing and mature rat brains. J Chem Neuroanat 12: 113-122.

Pacey LKK, Doering LC. 2007. Developmental expression of FMRP in the astrocyte lineage: Implications for fragile $\mathrm{X}$ syndrome. Glia 55: 1601-1609.

Pantazopoulos H, Woo T-UW, Lim MP, Lange N, Berretta S. 2010. Extracellular matrix-glial abnormalities in the amygdala and entorhinal cortex of subjects diagnosed with schizophrenia. Arch Gen Psychiatry 67: 155-166.

Parpura V, Haydon PG. 2009. Astrocytes in (patho)physiology of the nervous system. Springer, New York.

Patel SC, Asotra K, Patel YC, Patel RC, Suresh S. 1994. 25 Hydroxycholesterol induces reorganization of lysosomes in normal but not Niemann-Pick disease type C astrocytes. Neuroreport 5: 2121-2124.

Patel SC, Suresh S, Kumar U, Hu CY, Cooney A, BlanchetteMackie EJ, Neufeld EB, Patel RC, Brady RO, Patel YC, et al. 1999. Localization of Niemann-Pick C1 protein in astrocytes: Implications for neuronal degeneration in NiemannPick type C disease. Proc Natl Acad Sci 96: 1657-1662.

Petzold GC, Murthy VN. 2011. Role of astrocytes in neurovascular coupling. Neuron 71: 782-797.

Pfrieger FW. 2009. Role of glial cells in the formation and maintenance of synapses. Brain Res Brain Res Rev 63: 3946.

Pfrieger FW, Barres BA. 1997. Synaptic efficacy enhanced by glial cells in vitro. Science 277: 1684-1687.

Pierfelice T, Alberi L, Gaiano N. 2011. Notch in the vertebrate nervous system: An old dog with new tricks. Neuron 69: 840-855.

Prince E, Ring H. 2011. Causes of learning disability and epilepsy: A review. Curr Opin Neurol 24: 154-158.

Pringle NP, Yu W-P, Howell M, Colvin JS, Ornitz DM, Richardson WD. 2003. Fgfr3 expression by astrocytes and their precursors: Evidence that astrocytes and oligodendrocytes originate in distinct neuroepithelial domains. Development 130: 93-102.
Prochiantz A, Barbin G, Rousselet A, Chamak B, Fetler L. 1987. Further studies on the role of astroglia in brain neurons maturation and morphogenesis. J Physiol 82: 291-293.

Quaegebeur A, Lange C, Carmeliet P. 2011. The neurovascular link in health and disease: Molecular mechanisms and therapeutic implications. Neuron 71: 406-424.

Quinlan RA, Brenner M, Goldman JE, Messing A. 2007. GFAP and its role in Alexander disease. Exp Cell Res 313: 20772087.

Raedler TJ, Knable MB, Weinberger DR. 1998. Schizophrenia as a developmental disorder of the cerebral cortex. Curr Opin Neurobiol 8: 157-161.

Raff MC, Miller RH, Noble M. 1983. A glial progenitor cell that develops in vitro into an astrocyte or an oligodendrocyte depending on culture medium. Nature 303: 390-396.

Rakic P. 2007. The radial edifice of cortical architecture: From neuronal silhouettes to genetic engineering. Brain Res Brain Res Rev 55: 204-219.

Reichenbach A, Derouiche A, Kirchhoff F. 2010. Morphology and dynamics of perisynaptic glia. Brain Res Brain Res Rev 63: 11-25.

Ross SE, Greenberg ME, Stiles CD. 2003. Basic helix-loop-helix factors in cortical development. Neuron 39: 13-25.

Rowitch DH. 2004. Glial specification in the vertebrate neural tube. Nat Rev Neurosci 5: 409-419.

Rowitch DH, Kriegstein AR. 2010. Developmental genetics of vertebrate glial-cell specification. Nature 468: 214-222.

Roybon L, Hjalt T, Christophersen NS, Li J-Y, Brundin P. 2008. Effects on differentiation of embryonic ventral midbrain progenitors by Lmx1a, Msx1, Ngn2, and Pitx3. I Neurosci 28: $3644-3656$

Rubenstein JLR. 2010. Three hypotheses for developmental defects that may underlie some forms of autism spectrum disorder. Curr Opin Neurol 23: 118-123.

Saijo K, Winner B, Carson CT, Collier JG, Boyer L, Rosenfeld MG, Gage FH, Glass CK. 2009. A Nurr1/CoREST pathway in microglia and astrocytes protects dopaminergic neurons from inflammation-induced death. Cell 137: 47-59.

Sardi SP, Murtie J, Koirala S, Patten BA, Corfas G. 2006. Presenilindependent ErbB4 nuclear signaling regulates the timing of astrogenesis in the developing brain. Cell 127: 185-197.

Schummers J, Yu H, Sur M. 2008. Tuned responses of astrocytes and their influence on hemodynamic signals in the visual cortex. Science 320: 1638-1643.

Shaham S. 2006. Glia-neuron interactions in the nervous system of Caenorhabditis elegans. Curr Opin Neurobiol 16: $522-528$.

Shibata T, Yamada K, Watanabe M, Ikenaka K, Wada K, Tanaka $\mathrm{K}$, Inoue Y. 1997. Glutamate transporter GLAST is expressed in the radial glia-astrocyte lineage of developing mouse spinal cord. J Neurosci 17: 9212-9219.

Shu T, Butz KG, Plachez C, Gronostajski RM, Richards LJ. 2003. Abnormal development of forebrain midline glia and commissural projections in Nfia knock-out mice. J Neurosci 23: 203-212.

Sofroniew MV. 2009. Molecular dissection of reactive astrogliosis and glial scar formation. Trends Neurosci 32: 638-647.

Somjen CG. 1988. Nervenkitt: Notes on the history of the concept of neuroglia. Glia 1: 2-9.

Stahl N, Yancopoulos GD. 1994. The tripartite CNTF receptor complex: Activation and signaling involves components shared with other cytokines. I Neurobiol 25: 1454-1466.

Steele-Perkins G, Plachez C, Butz KG, Yang G, Bachurski CJ, Kinsman SL, Litwack ED, Richards LJ, Gronostajski RM. 2005. The transcription factor gene Nfib is essential for both 
lung maturation and brain development. Mol Cell Biol 25: 685-698.

Stevens B, Allen NJ, Vazquez LE, Howell GR, Christopherson KS, Nouri N, Micheva KD, Mehalow AK, Huberman AD, Stafford B, et al. 2007. The classical complement cascade mediates CNS synapse elimination. Cell 131: 1164-1178.

Stolt CC, Lommes P, Sock E, Chaboissier M-C, Schedl A, Wegner M. 2003. The Sox 9 transcription factor determines glial fate choice in the developing spinal cord. Genes Dev 17: 1677-1689.

Sun Y, Nadal-Vicens M, Misono S, Lin MZ, Zubiaga A, Hua X, Fan G, Greenberg ME. 2001. Neurogenin promotes neurogenesis and inhibits glial differentiation by independent mechanisms. Cell 104: 365-376.

Sur M, Rubenstein JLR. 2005. Patterning and plasticity of the cerebral cortex. Science 310: 805-810.

Takano T, Tian G-F, Peng W, Lou N, Libionka W, Han X, Nedergaard M. 2006. Astrocyte-mediated control of cerebral blood flow. Nat Neurosci 9: 260-267.

Tidyman WE, Rauen KA. 2009. The RASopathies: Developmental syndromes of Ras/MAPK pathway dysregulation. Curr Opin Genet Dev 19: 230-236.

Tien A, Tsai H, Molofsky AV, McMahon M, Foo L, Kaul A, Doughherty JD, Heintz N, Gutmann DH, Barres BA, et al. 2012. Regulated temporal-spatial astrocyte precursor cell proliferation involves BRAF signalling in mammalian spinal cord. Development (in press).

Ullian EM, Sapperstein SK, Christopherson KS, Barres BA. 2001. Control of synapse number by glia. Science 291: 657661.

Ullian EM, Harris BT, Wu A, Chan JR, Barres BA. 2004. Schwann cells and astrocytes induce synapse formation by spinal motor neurons in culture. Mol Cell Neurosci 25: 241-251.

Vangeison G, Rempe DA. 2009. The Janus-faced effects of hypoxia on astrocyte function. Neuroscientist 15: 579-588.

Vaughn JE, Pease DC. 1967. Electron microscopy of classically stained astrocytes. J Comp Neurol 131: 143-154.

Vaughn JE, Peters A. 1967. Electron microscopy of the early postnatal development of fibrous astrocytes. Am J Anat 121: 131-152.

Visanji NP, Wong JC, Wang SX, Cappel B, KleinschmidtDemasters BK, Handler MH, Ochi A, Otsubo H, Rutka JT, Go C, et al. 2012. A proteomic analysis of pediatric seizure cases associated with astrocytic inclusions. Epilepsia 53: e50-e54. doi: 10.1111/j.1528-1167.2011.03369.x.

Walsh CA, Morrow EM, Rubenstein JLR. 2008. Autism and brain development. Cell 135: 396-400.

Wang DD, Bordey A. 2008. The astrocyte odyssey. Prog Neurobiol 86: 342-367.

Watkins TA, Emery B, Mulinyawe S, Barres BA. 2008. Distinct stages of myelination regulated by $\gamma$-secretase and astrocytes in a rapidly myelinating CNS coculture system. Neuron 60: $555-569$.

Weinberger DR, Lipska BK. 1995. Cortical maldevelopment, anti-psychotic drugs, and schizophrenia: A search for common ground. Schizophr Res 16: 87-110.

Wetherington J, Serrano G, Dingledine R. 2008. Astrocytes in the epileptic brain. Neuron 58: 168-178.

Wilczynska KM, Singh SK, Adams B, Bryan L, Rao RR, Valerie K, Wright S, Griswold-Prenner I, Kordula T. 2009. Nuclear factor I isoforms regulate gene expression during the differentiation of human neural progenitors to astrocytes. Stem Cells 27: 1173-1181.

Wolburg H, Noell S, Mack A, Wolburg-Buchholz K, FallierBecker P. 2009. Brain endothelial cells and the glio-vascular complex. Cell Tissue Res 335: 75-96.
Wu H-H, Bellmunt E, Scheib JL, Venegas V, Burkert C, Reichardt LF, Zhou Z, Fariñas I, Carter BD. 2009. Glial precursors clear sensory neuron corpses during development via Jedi-1, an engulfment receptor. Nat Neurosci 12: 1534-1541.

Yeh T-H, Lee DY, Gianino SM, Gutmann DH. 2009. Microarray analyses reveal regional astrocyte heterogeneity with implications for neurofibromatosis type 1 (NF1)-regulated glial proliferation. Glia 57: 1239-1249.

Zhang Y, Barres BA. 2010. Astrocyte heterogeneity: An underappreciated topic in neurobiology. Curr Opin Neurobiol 20: 588-594.

Zhou HF, Lee LH, Lund RD. 1990. Timing and patterns of astrocyte migration from xenogeneic transplants of the cortex and corpus callosum. J Comp Neurol 292: 320-330.

Zlokovic BV. 2008. The blood-brain barrier in health and chronic neurodegenerative disorders. Neuron 57: 178-201.

Zoghbi HY. 2009. Rett syndrome: What do we know for sure? Nat Neurosci 12: 239-240. 


\section{Errata}

Genes \& Development 26: 891-907 (2012)

Astrocytes and disease: a neurodevelopmental perspective

Anna V. Molofsky, Robert Krencik, Erik M. Ullian, Hui-hsin Tsai, Benjamin Deneen, William D. Richardson, Ben A. Barres, and David H. Rowitch

In this article, Robert Krencik's name was misspelled and Erik M. Ullian's middle initial was missing. The corrected list of the authors' names appears above.

Genes \& Development 26(12): fmiv

In the cover caption for the June 15,2012, issue, the third sentence should read as noted below. This change is reflected in the online cover caption for the issue.

The $\beta_{1}$ integrin-positive melanoma cell surface is seen in the center of the image (large, red), with smaller shed microvesicles (red) around the cell. 


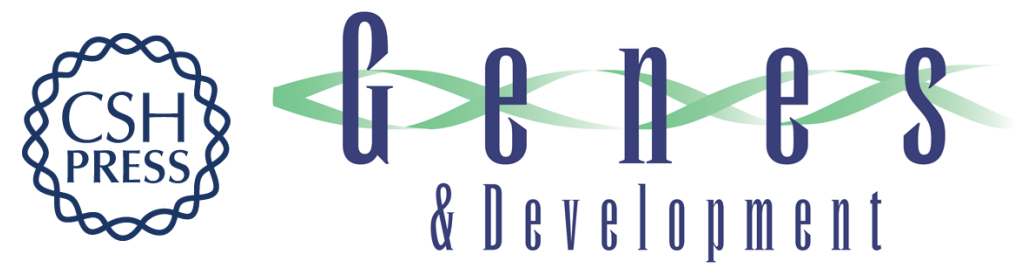

\section{Astrocytes and disease: a neurodevelopmental perspective}

Anna V. Molofsky, Robert Krenick, Erik Ullian, et al.

Genes Dev. 2012, 26:

Access the most recent version at doi:10.1101/gad.188326.112

Related Content Astrocytes and disease: a neurodevelopmental perspective Anna V. Molofsky, Robert Krencik, Erik M. Ullian, et al. Genes Dev. July , 2012 26: 1508

References This article cites 150 articles, 33 of which can be accessed free at: http://genesdev.cshlp.org/content/26/9/891.full.html\#ref-list-1

Articles cited in: http://genesdev.cshlp.org/content/26/9/891.full.html\#related-urls

\section{License}

Email Alerting

Receive free email alerts when new articles cite this article - sign up in the box at the top Service right corner of the article or click here.

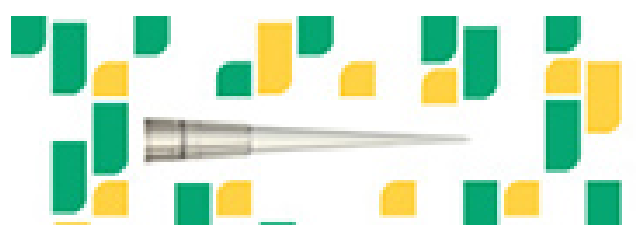

Focused on your science. 